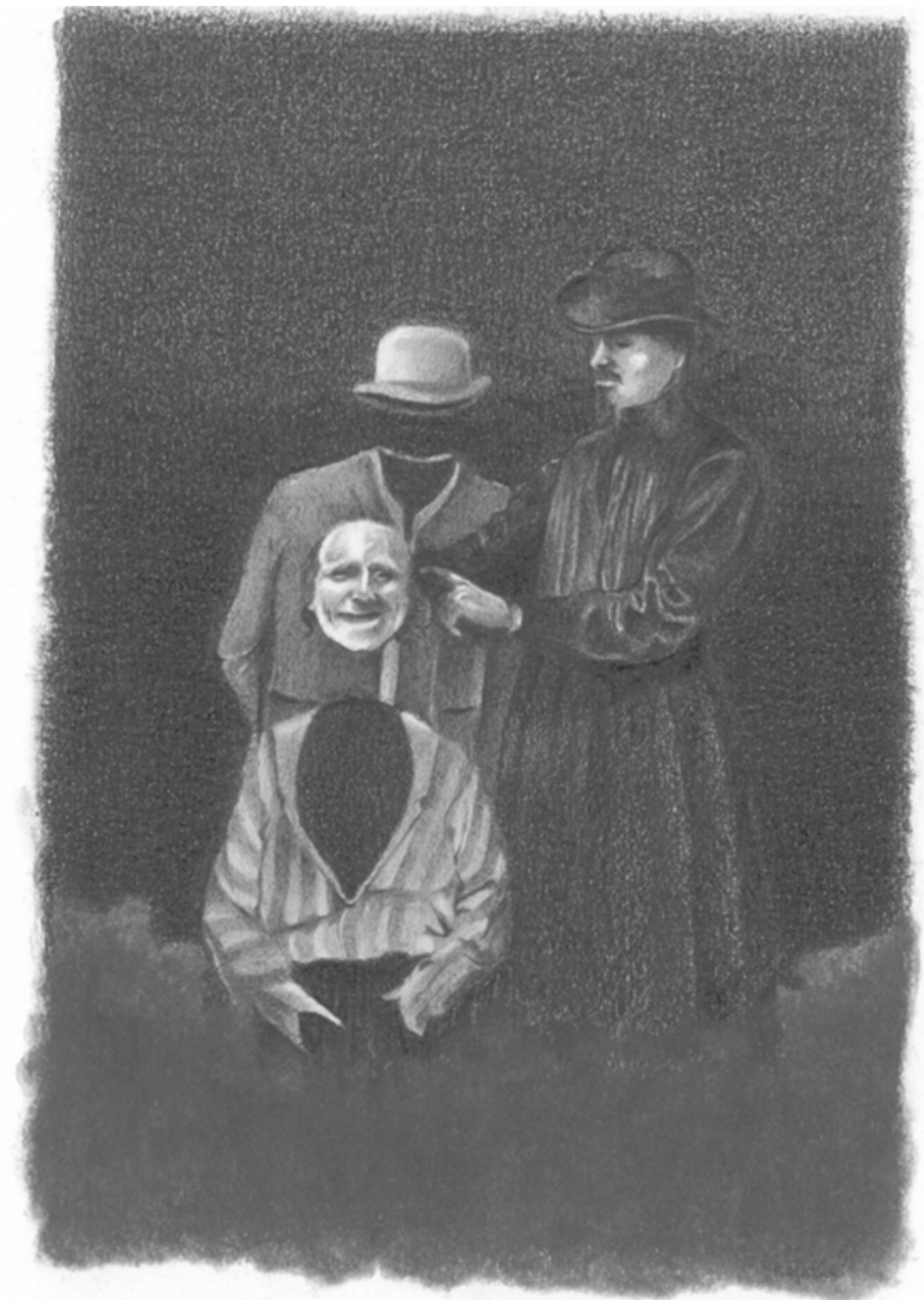

Luis Fernando Salazar Espinosa

Sin título

De la serie Psiquis

Lápiz sobre papel

$18 \times 15 \mathrm{~cm}$

2017

Medellín 


\title{
Oscilar entre la esperanza y la incertidumbre. Actitudes sobre trayectorias, autoridades, medidas de protección e (in)seguridad de solicitantes centroamericanos de la condición de refugio en México*
}

\author{
Luis Alfredo Arriola Vega (México)** \\ Santiago Martínez Junco (México) ${ }^{* * *}$
}

\section{Resumen}

Durante y posterior al proceso de solicitar la condición de refugiado en México los centroamericanos que inician ese procedimiento viven en situación de (in) seguridad. Tienen la expectativa de ser acogidos en dicho país, pero simultáneamente el contexto en el cual solicitan esa medida de protección es incierto. Su existencia transita entre la esperanza y la indeterminación. Ese vaivén queda revelado en las actitudes que manifiestan salvadoreños, hondureños y guatemaltecos solicitantes de la condición de refugio entrevistados en Tapachula, Chiapas y Tenosique, Tabasco. Por una parte, la posibilidad de que se les otorgue la condición genera una perspectiva esperanzadora entre los solicitantes; por otra parte, las tasas de rechazo, lo prolongado que suele ser el proceso y las condiciones desfavorables durante la espera, así como las limitadas oportunidades para la sobrevivencia, ensombrecen ese anhelo. El análisis de los datos muestra que su capacidad agentiva se ve limitada, mas no plenamente suprimida. Algunos solicitantes de la condición hacen uso de capacidad agentiva instrumental y «apática», mientras que otros recurren a un discurso contestatario para sobrellevar el desaliento que permea su condición adversa.

\section{Palabras clave}

Migración; Política Migratoria; Dinámicas Trasfronterizas; Refugiado, Centroamérica; México.

\footnotetext{
* El artículo es resultado del sub-proyecto El entorno de vulnerabilidad en que se encuentran migrantes centroamericanos a su paso por México: solicitantes de la condición de refugio y condición de visitante por razones humanitarias, como parte de un proyecto mayor denominado Miradas sobre la vulnerabilidad en el sureste de México. Mega diversidad y prácticas alternativas para el bienestar, 2015-2018, financiado por El Colegio de la Frontera Sur.

** Magíster y doctorado en Antropología. Profesor e investigador del Departamento de Sociedad y Cultura, y miembro del grupo Estudios de Migración y Procesos Transfronterizos, El Colegio de la Frontera Sur, México. Correo electrónico: larriola@ecosur.mx - Orcid: 0000-0001-7571-3759 - Google Scholar: https://scholar.google.com.mx/citations?user=QGFp4U0AAAAJ\&hl=es

*** Licenciado en Psicología. Magíster en Ciencias de la Educación y magíster en Terapia Infantil. Docente en la Facultad de Ciencias Agrícolas, Universidad Autónoma de Chiapas, México. Correo electrónico: santiago.martínez@unach.mx
} 
Fecha de recepción: julio de 2019

- Fecha de aprobación: noviembre de 2019

Cómo citar este artículo

Arriola Vega, Luis Alfredo y Martínez Junco, Santiago. (2020). Oscilar entre la esperanza y la incertidumbre. Actitudes sobre trayectorias, autoridades, medidas de protección e (in)seguridad de solicitantes centroamericanos de la condición de refugio en México. Estudios Políticos (Universidad de Antioquia), 57, pp. 175-208. DOI: 10.17533/udea.espo.n57a09

\title{
Between Hope and Uncertainty. Attitudes Toward Trajectories, Authorities, International Protection Protocols, and (In)Security among Central American Refugee-Seekers in Mexico
}

\begin{abstract}
Central Americans who seek refugee status in Mexico live in a state of (in) security during and after the process is over. They expect to be granted protection, yet the context in which they look for refugeehood is uncertain. Their lives swing back and forth between hope and incertitude. Interviews with Salvadorian, Honduran,

[176] and Guatemalan refugee seekers in Tapachula, Chiapas, and Tenosique, Tabasco reveal attitudes indicative of such a state of fluctuation. On the one hand, the possibility of attaining a refugee status raises hopes among claimants. On the other hand, Mexico's high rejection rates, the long-drawn-out time the process involves, and the unfavorable conditions people face during the period they wait for an answer- including the difficulty of finding employment-, discourage refugee seekers. Analysis of interview data shows that under the aforementioned circumstances the ability to react, i.e. to exert agency, is limited, yet not altogether suppressed. Some refugee applicants turn to an «apathetic» type of agency, an instrumental one, while others appeal to an anti-establishment narrative to endure their precarious and adverse circumstances.
\end{abstract}

\section{Keywords}

Migration; Migration Politics; Cross-Border Dynamics; Refugees; Central America; Mexico. 


\section{Introducción}

Generalmente se conocen las apreciaciones que se forman las personas de las sociedades receptoras sobre los migrantes que llegan a esas sociedades. Se sabe menos sobre la manera en que los migrantes perciben sus propias experiencias. Este trabajo pretende vislumbrar las percepciones que los solicitantes de la condición de refugio se forman sobre las circunstancias, personas e instituciones que enfrentan en el proceso de obtener la condición de refugiado. Las actitudes sobre el cruce de una frontera, la llegada al lugar donde se inicia el procedimiento — trámite — para solicitar refugio, las autoridades con las cuales se relacionan los solicitantes de la condición, las circunstancias de vida donde se realiza el procedimiento y las expectativas sobre el resultado de este revelan una compleja existencia caracterizada por su vaivén entre la esperanza y la incertidumbre.

Obtener la condición genera una expectativa optimista que se manifiesta — si bien en ocasiones es tenue - en las actitudes. Altas tasas de rechazo a las solicitudes, lo prolongado que suele ser el proceso, las condiciones adversas de la espera y limitadas oportunidades para la sobrevivencia económica mientras se obtiene una respuesta al procedimiento ensombrecen ese anhelo. La incertidumbre es parte de la inseguridad que permea muchas esferas de la vida. El solicitante tiene inseguridad jurídica al no contar con documentos que le permitan un estatus legal; la inseguridad económica se experimenta porque sin documentos es prácticamente imposible solicitar empleo formal; se sufre inseguridad social porque el Estado no brinda apoyo en rubros como vivienda y educación. Las ciudades donde se realizó el estudio - Tapachula, Chiapas y Tenosique, Tabasco, México — también son ámbitos de inseguridad debido a los abusos de los que pueden ser objeto los solicitantes por parte de algunos representes estatales, la xenofobia que expresan ciertos sectores de la población local hacia los solicitantes o el temor que infunden grupos criminales entre los centroamericanos. En resumen, la existencia de un solicitante de la condición se caracteriza por su estado de precariedad. Así, las respuestas de los informantes denotaban muchas actitudes ambiguas y negativas.

A través de los resquicios de este panorama adverso se hacen manifiestas actitudes proactivas entre algunos de los solicitantes de la condición. Son simples formas de luchar en el ámbito discursivo que muestran cómo subyace cierta capacidad agentiva, la cual no siempre se hace visible o patente de otra forma. Las actitudes en las que se manifiesta esa capacidad agentiva restringida 
expresan que ellos también reflexionan críticamente y son contestatarios de narrativas normalizadas, de discursos en los cuales son representados como «vulnerables» o «víctimas», ya que ellos no lo asumen así. Son voces de resistencia que apuestan a la esperanza, sin perder la perspectiva de la incertidumbre que sobrellevan.

\section{Aspectos metodológicos}

En Tapachula, el acceso a solicitantes de la condición de refugio se logró a través de instituciones que trabajaban con esa población. En Tenosique se obtuvo el apoyo de un refugio para migrantes. Los nombres de estas instancias y de las personas que accedieron a ser entrevistadas se han omitido por razones de confidencialidad. El grupo de entrevistados no es representativo de todos los solicitantes, pero sí ilustra ciertas condiciones comunes que experimentan estas personas. Tampoco se ambicionaba que los resultados fueran generalizables a partir de un estudio inicial, pero sí que fueran particulares para la situación, en el tiempo y en el espacio de los participantes. Esto es importante dado el contexto temporal de la investigación. Por ejemplo, a partir de la segunda mitad de 2018 las condiciones cambiaron en Tapachula con el surgimiento de las caravanas [178] migrantes que atravesaron México.

Se podría argumentar que este estudio adolece de un problema metodológico al no haber podido hacer una escogencia al azar del grupo objeto de investigación. La imposibilidad de tener acceso a solicitantes de la condición por canales oficiales obligó a la búsqueda de otras vías. Por ello se recurrió a instancias de la sociedad civil. Catorce solicitantes eran originarios de Honduras, ocho de El Salvador y dos de Guatemala, con edades entre 15 y 55 años. La heterogeneidad del grupo quedó reflejada en la inclusión de personas heterosexuales, de la comunidad LGBTI+, un hombre originario del pueblo garinagu (Honduras) y uno proveniente del pueblo k'iché (Guatemala).

La investigación tuvo lugar entre noviembre de 2015 y agosto de 2017. El instrumento principal, la entrevista semiestructurada, se dividió en dos partes: la primera sección —el material principal para el análisis aquí presentado- recopiló datos con la técnica «asociación libre» (Galton, 1879), a través de lo que denominamos «reactivos», de tal manera que el(la) entrevistado(a) expresara lo primero que se le viniera a la mente al escuchar esas palabras; la segunda parte de la entrevista contenía preguntas sobre la historia de migración de la persona, las razones que motivaron su huida 
del país de origen, su condición económica y emocional, la fase en que se encontraba el procedimiento al momento de la entrevista y las expectativas futuras en caso de que la persona fuera reconocida como refugiada o no. La información ampliada de la segunda parte ayudó a comprender mejor la razón de ciertas respuestas obtenidas por medio de asociación libre, como se demuestra más adelante.

\section{Percepciones y actitudes}

Cada uno de nosotros organiza, interpreta y analiza de manera distinta los estímulos del entorno circundante. El cerebro «construye» la realidad a partir de información que filtra y contrasta con la memoria - recuerdos- y otros elementos, como las expectativas, para ofrecernos «la mejor conjetura de la realidad» (Ornstein, 1975, citado en Gross, 2007). Si bien la percepción individual es subjetiva, selectiva y temporal, también entran en juego los valores, las motivaciones, las necesidades y las actitudes.

Desde la psicología social, las actitudes están relacionadas con la valoración o evaluación positiva o negativa de un objeto, una persona, un grupo o un tema (Franzoi, 2007, p. 172). Las actitudes son válidas y apropiadas en la medida en que las mismas creencias y opiniones se comparten en el interior de un grupo (Festinger, Schachter y Back, 1950). Para algunos psicólogos (Kimble et al., 2002, p. 136), las actitudes son la suma de factores de orden cognoscitivo - las creencias - y de factores emocionales - los valores- Otros especialistas consideran que la actitud puede ser reflejo de los sentimientos, las emociones y la conducta, pero la mayoría de los psicólogos hoy en día optan por una definición más simple, como la ya expuesta (Franzoi, 2007, p. 172).

Stephen Franzoi (2007) identifica varios tipos de actitudes: las implícitas se activan de manera automática desde la memoria, con frecuencia sin que la persona se dé cuenta que las posee; las explícitas son actitudes que se tiene de manera consciente; las duales resultan de la conjunción simultánea de actitudes implícitas y explícitas, y que en ocasiones pueden ser contradictorias o ambivalentes hacia el mismo objeto.

Las actitudes pueden cumplir varias funciones psicológicas, entre ellas encontrarle sentido al mundo que nos rodea, conseguir la aceptación del prójimo o formarse ciertas ideas para fortalecer la autoestima (Franzoi, 2007, p. 186); además, conllevan un sentido utilitario porque sirven como mecanismos 
que enfrentar conflictos emocionales y para proteger a la autoestima de problemas internos y de la realidad desagradable. Una actitud de aceptación a las vulnerabilidades que enfrenta un migrante tiene su correspondencia en estrategias y formas de defensa ante los riesgos que surgen en la travesía. Es del interés de este trabajo entender la forma en que alguien se concibe o se percibe emocionalmente frente a un concepto, institución o persona expresado a través de una actitud.

¿Qué determina las actitudes? Las personas migrantes representan la realidad como ellos la entienden, realidad que es moldeada por sus experiencias previas. Esto tiene que ver con aspectos tales como su historia migratoria, con el contexto del país de origen, con la información disponible sobre el lugar de destino. Entre los solicitantes de la condición originarios de Centroamérica hay otros elementos que también influyen en la conformación de las actitudes, verbigracia el periodo en espera en el que ellos se encuentran y el cual influye en una visión adversa o contradictoria sobre el lugar de donde provienen, el proceso de solicitar refugio $u$ otras medidas de protección, el destino temporal —México—, y su relación con las autoridades. Las actitudes permiten entrever la forma en que los solicitantes de refugio edifican visiones de su experiencia de movilidad.

\section{Revisión de la literatura}

Las investigaciones sobre las percepciones y las actitudes se han concentrado en cómo se percibe a los refugiados, pero son pocos los trabajos alusivos a la perspectiva que ellos mismos tienen sobre el proceso de movilidad forzada. Se encontraron estudios de corte cualitativo ${ }^{1}$ sobre las percepciones de poblaciones migrantes desde los países receptores (Amenusca, 2011; Delgado, 2008), la relación entre discriminación y bienestar (Fozdar y Torezani, 2008), las percepciones desde el propio país de origen (Masanet, 2006), la ansiedad, prejuicios y amenaza que perciben universitarios en migrantes no autorizados y refugiados (Murray y Marx, 2013). Se señalan aquí dos ejemplos de investigaciones específicas sobre refugiados: uno examina las apreciaciones en Líbano sobre los refugiados sirios como factor de riesgo (Braithwaite et al., 2019); el otro analiza los contrastes que se forman los

\footnotetext{
${ }^{1}$ La Encuesta Mundial de Valores (WVS, s. f.) es ejemplo de otra forma de medir y evaluar las actitudes por medio de un muestreo estadístico a escala internacional. Entre otras cosas, la Encuesta indaga sobre las opiniones que las persones tienen acerca de los inmigrantes.
} 
ciudadanos de Dinamarca e Israel hacia solicitantes de refugio (Hercowitz, Raijman y Davidov, 2017).

Hay otras vías posibles para aprehender las percepciones sobre los migrantes y refugiados, tales como el análisis de textos a través de la revisión de información contenida en los medios de comunicación (Morales, 2015; Fajardo y Soriano, 2016; Galindo, 2019) y el análisis del discurso (Clark-Kazak, 2009). Existe también el uso extendido del modelo de las representaciones sociales (RS) (Moscovici, 1961), a partir del cual ha dominado el interés por conocer qué piensan las sociedades receptoras sobre los migrantes y no al revés. Dan cuenta de este enfoque estudios sobre representaciones de los ecuatorianos en España (Pedone, 2002; Montero, 2006); extranjeros que han ido a Chile (Martínez, 2006; Torres y Garcés, 2013) o mujeres centroamericanas en Chiapas (Cruz, 2011). Marysol Patiño (2005) realizó un trabajo que representa una excepción a la tendencia dominante, al documentar los imaginarios que los jóvenes ecuatorianos indígenas emigrados a Francia se formaban sobre su lugar de origen, la sociedad a la que llegaban y sus expectativas. Se descartó el uso de las RS en este trabajo por algo advertido por el propio precursor: las RS son inestables y, por tanto, difíciles de aprehender (Moscovici, 1961; Moscovici y Marková, 1998).

La migración es un fenómeno complejo y en constante transformación. En ese entramado de elementos - la temporalidad de una trayectoria, los obstáculos a la movilidad e incluso aspectos personales como pueden ser la edad o la identidad de género, entre otros - resulta sumamente complejo «describir y explicar las relaciones entre los elementos mentales y materiales en la vida social (Moscovici, 1988), tendiendo [con ello] un puente entre el individuo, la cultura y la historia, es decir, entre la subjetividad y la vida social de los seres humanos» (Avendaño, Krauser y Wrinkler, 1993, p. 108). Dicho de otra forma, se complica «vincular el polo psicológico con el polo social» (p. 113). El eslabón más débil, del cual adolecen muchos de los estudios en los cuales se emplea la teoría de RS, es precisamente la ausencia de esa interfaz entre las esferas psicológica y social para ofrecer un modelo explicativo coherente (Quezada, 2007).

Para la zona de interés de esta investigación existen pocos trabajos sobre percepciones y actitudes relativas a personas migrantes. Uno de ellos es el estudio de Diego Ramos, Enrique Coraza y Santiago Martínez (2018), 
el cual recoge percepciones diversas en dos ciudades fronterizas adyacentes —Ciudad Hidalgo, México, y Tecún Umán, Guatemala-. En ese estudio se preguntó a los habitantes locales sobre las autoridades estatales en la frontera, tema abordado en esta investigación. Los entrevistados calificaron favorablemente a los militares porque representaban seguridad y ausencia de corrupción, en oposición a la Policía municipal. Estos últimos eran «fáciles de corromper» (Ramos, Coraza y Martínez, 2018, p. 68). Esta investigación contribuye a llenar ese vacío detectado en la literatura al presentar las actitudes primarias que construyen los solicitantes de la condición de refugiado sobre: a) su trayectoria migratoria; b) el proceso de solicitar la condición; c) las autoridades con las que tienen que lidiar; y d) sobre su percepción de seguridad e inseguridad.

\section{Aspectos contextuales}

\subsection{Condiciones del desplazamiento}

Las causas de fondo que dieron origen a los conflictos armados que vivieron Guatemala y El Salvador en las décadas de 1970 y 1980 continúan sin ser resueltas y, por ende, persisten los problemas. Condiciones económicas

[182 ] precarias, instituciones estatales débiles, corrupción gubernamental, falta de acceso a programas sociales básicos entre los sectores más necesitados y otras dificultades han provocado que la gente emigre en grandes números. Si bien Honduras no experimentó una situación directa de guerra, el deterioro socioeconómico progresivo del país en las últimas dos décadas agravó la situación de la población más pobre, provocando la emigración masiva (Booth, Wade y Walker, 2014). Asimismo, estas sociedades experimentan altos niveles de violencia estructural, simbólica, de género y, en general, un contexto de alta criminalidad (Hiskey et al., 2018). Hace cuatro décadas la gente salía tanto por razones económicas como políticas. Hoy en día sobresalen, al menos, dos cambios cualitativos como parte del fenómeno migratorio: a) tanto el factor económico como el conjunto de violencias detonan la migración desde esos tres países; y b) muchas personas no necesariamente contemplan como destino anhelado Estados Unidos, pero sí consideran como destino posible a México. En ese contexto, las percepciones y actitudes de los migrantes están moldeadas por sociedades de origen que se encuentran en constantes crisis y por un horizonte poco alentador de cambios. Por ello, no sorprende que actitudes negativas predominen en las respuestas de los sujetos. 


\subsection{Situación del acceso al refugio en México}

Existen varias figuras en la normatividad del Estado mexicano para proteger a las personas en situación de movilidad forzada: condición de refugiado, condición de visitante por razones humanitarias $(\mathrm{CVRH})$ y protección complementaria. ${ }^{2}$ Este trabajo se enfoca en la primera medida. En caso de una respuesta negativa — no reconocimiento - al procedimiento, el solicitante podía presentar una apelación —revisión—, con una extensión de 45 días hábiles. Ante un fallo negativo, tenía que iniciar el procedimiento otra vez. Sin embargo, en los hechos, cada procedimiento podía tomar de dos a tres meses (Human Rights Watch, 2016, marzo 31).

Cuando la resolución era positiva —refugio otorgado-, las opciones variaban dependiendo de las circunstancias personales o familiares. La gente se inclinaba, mayormente, por moverse a otra parte de México porque consideraban que no existían las condiciones mínimas para re-hacer su vida en Tenosique o Tapachula. Al momento de realizar la investigación muy pocos podían realizar el traslado inmediatamente. Desde la perspectiva de los centroamericanos que iniciaban el procedimiento, puede decirse que el panorama sobre el régimen de refugio en México aparecía como relativamente adverso. Los datos oficiales de México mostraban que de 14603 solicitudes en 2017 —de todas las nacionalidades— se concedió el estatus a 4195 solicitantes (28,7\%), mientras que a 2247 (15,3\%) les fue negado; aproximadamente 4495 $(30,7 \%)$ abandonaron o desistieron de continuar con el trámite; otros 2075 $(14,2 \%)$ aparecían como casos pendientes de resolución y el resto obtuvieron la protección complementaria (Comar, 2019, enero 14). Las luces y sombras que caracterizan el proceso para obtener alguna medida de protección no pasaban inadvertidas entre los entrevistados. Las percepciones se ubicaban entre una expectativa remota y una batalla incierta y ardua de ganar. Esto también tiene que ver con un asunto crítico: en muchos casos, en todo el mundo, los solicitantes de medidas de protección poseen nulo o escaso conocimiento sobre las políticas migratorias y de refugio de los países a los cuales se dirigen (Crawley y Hagen-Zanker, 2019, p. 27). La ignorancia sobre

\footnotetext{
${ }^{2}$ La CVRH se otorga cuando un migrante ha sido víctima o testigo de un crimen. La protección complementaria se extiende a personas para quienes, no obstante habérseles negado el estatus de refugiado, se considera que existen elementos suficientes que los hacen acreedores de protección porque corren peligro si regresan a su país.
} 
los procedimientos influye en las actitudes que los solicitantes de la condición muestran al respecto, tal como se observa más adelante.

\section{Régimen «securitario», autoridades e (in)seguridad}

A pesar de los importantes avances en materia de refugio y otras medidas de protección en México, el manejo de la migración no autorizada en el país en tiempo reciente ha sido a través de políticas más bien restrictivas, materializándose en acciones de contención permanente — garitas, retenes, redadas y deportaciones - y otras coyunturales, pero de gran envergadura, como el Programa Frontera Sur (Arriola, 2018). Como parte del programa, en determinados momentos las autoridades mexicanas detuvieron más migrantes centroamericanos que sus contrapartes estadounidenses.

En este texto se argumenta que en México existe un régimen «securitario» en la gestión migratoria de personas migrantes en situación no autorizada, porque la seguridad se concibe y se aplica desde una visión de control, por encima de otros esquemas, por ejemplo, el modelo de la seguridad multidimensional (Wæver, 1995; Buzan, Wæver y de Wilde, 1998; Watson, 2009). La seguridad multidimensional tiene una relación cercana [184 ] con la noción de seguridad humana, promulgada en 1994 por la ONU (Nef, 1999). Según algunos autores (Basok y Rojas, 2018, p. 1275), la tendencia «securitaria» para atender la migración ha seguido un patrón de escalada en la frontera sur mexicana en las últimas décadas, otros (Treviño-Rangel, 2016) están en desacuerdo.

Al momento de realizar esta investigación, la seguridad estatal en México estaba a cargo de policías federales, estatales y municipales, elementos de la Secretaría de la Defensa y de la Secretaría de Marina. Aunque todos tienen claramente definidas áreas de acción y atribuciones específicas, sus tareas relativas a salvaguardar el orden y la seguridad los colocan en situaciones en las cuales entran en contacto con población migrante no autorizada. Ninguno de estos cuerpos tiene autorización para aprehender migrantes, pero en los hechos la discrecionalidad y el abuso de poder dan lugar a arbitrariedades en contra de esas personas. Esto influye en las actitudes de los migrantes.

El uso del vocablo (in)seguridad denota una tensión subyacente. El paréntesis plantea la indeterminación que hay en la posibilidad de que un migrante pase de una condición de inseguridad - física, económica y jurídica - a una de seguridad o viceversa, dependiendo del contexto que 
enfrente —adverso o favorable- de su condición migratoria —autorizado-no autorizado-, del éxito en las gestiones de la solicitud de refugio y de otros factores. La región fronteriza México-Guatemala representa un espacio de acogida porque existe la posibilidad de acceso a medidas de protección, pero también de rechazo vía la discriminación y la exclusión social, o bien por el régimen «securitizado» estatal (Coraza, 2018, p. 36). Los resultados de esta investigación hecen patente que la (in)seguridad es la condición en la que se debaten los solicitantes de refugio, la cual los hace manifestar actitudes contradictorias y negativas.

\section{Capacidad agentiva del sujeto migrante}

Con el término capacidad agentiva (CA) se da a entender que todo migrante es capaz de reaccionar o resistir para defenderse, para reivindicar algo, para luchar. La amplitud conceptual para concebir el nexo CA-migrantesrefugiados está plasmada en un creciente cuerpo de literatura (Gill, Caletrío y Mason, 2011, p. 307; O'Higgins, 2012, p. 81; Orgocka, 2012, p. 2; Stewart, 2005, p. 499). La CA pone de manifiesto que los migrantes no deben ser considerados seres carentes de iniciativa para enfrentar la adversidad y los desafíos que se les presentan. Es un recurso a su favor, si bien de alcance muchas veces limitado. Lisa Malkki (1995, p. 18) ha cuestionado aquella visión hegemónica en la que el migrante forzado es un sujeto apolítico, a-histórico. Ella refrenda que no debe ser así porque eso implica negar al individuo cualquier potencial de CA. Lo cierto es que demostrar CA puede ser considerado como una desventaja cuando se solicitan medidas de protección porque:

Cualquier evidencia de capacidad agentiva durante un viaje clandestino puede socavar el «estado de víctima» de un solicitante de asilo y con ello debilitar su derecho de reivindicar la condición de refugiado [Oxford, 2005, pp. 31-33]. Los migrantes deben actuar como el sujeto despolitizado que sufre y es incapaz de actuar y [que] necesita ser rescatado (Mainwaring, 2016, p. 2. Traducción propia).

Las respuestas de los participantes en este estudio muestran una amplia gama de actitudes, ya que algunos asumen una postura contestataria a su condición y al sistema, y el resto se expresan, en apariencia, como sujetos pasivos. Si bien a primera vista pareciera contrario al sentido común, la indiferencia en realidad puede encubrir una estrategia para autoproyectarse y conseguir un fin —obtener un estatus de protección—, algo así como una CA 
táctica (Utas, 2005) de índole «apática». En otro momento de la trayectoria migratoria esa misma persona puede asumir y expresar una actitud diferente, proactiva.

Y es que la posición que adopte un migrante puede estar determinada por las fuerzas que dinamizan el fenómeno migratorio y los cambios imprevistos que le acompañan. En ese contexto dinámico, existen factores sociales, económicos, políticos, ambientales que hacen a los migrantes cambiar rápidamente de parecer (McAuliffe y Jayasuriya, 2016, p. 57, citado en Crawley y Hagen-Zanker, 2019, p. 2). La oportunidad de un empleo, la posibilidad de la reunificación familiar, la probabilidad de continuar un viaje interrumpido o la inseguridad en el entorno suelen resultar cruciales para la toma de decisiones $y$, a su vez, la percepción de una trayectoria, de las autoridades, de los destinos anhelados u otros aspectos. He aquí un testimonio que encarna estas ideas:

Rina, Miguel y varios hijos llegaron a Tapachula solicitando la condición de refugiados. Ante el reactivo «refugio otorgado» la respuesta de Rina fue «esperanza». Ante el reactivo «refugio rechazado» respondió con la frase «¿A dónde ir?» Más adelante añadió que de serle otorgada la condición de refugiada lo que deseaba era ser reubicada a otro lugar. Sus planes en caso de negársele la condición contemplaban apelar y, a la vez, buscar a sus dos hijas que aún permanecían en El Salvador. A fines de mayo de 2016, ella y su familia consiguieron la condición. A lo largo de ese y el siguiente año siguió residiendo en Tapachula a la espera de lograr la reunificación familiar, algo que se materializó; sin embargo, no se sentía segura por la presencia de Maras [pandillas] en la colonia donde residía. Más adelante Rina consiguió ser trasladada a Saltillo, Coahuila. Desde nuestra conversación inicial Rina había dejado entrever que su propósito era intentar llegar a Tijuana, donde vivía una de sus hermanas. Poco a poco estaba logrando ese objetivo (comunicación personal, Tapachula, 17 de mayo, 2016 y 13 de mayo, 2017).

El fragmento anterior da cuenta de los reajustes que los sujetos migrantes hacen (Townsend y Oomen, 2015). El tiempo en espera posibilita a los solicitantes de la condición reconsiderar estrategias y planes, recalibrar la CA en la toma de decisiones con relación a destinos anhelados, rutas posibles, pausas en la movilidad, acceso a redes, entre otros. Las actitudes están marcadas por esa CA versátil, en función de un entorno cambiante. Conscientes del reto analítico que esa variabilidad conlleva, se realizó el 
primer acercamiento a las actitudes expresadas por los entrevistados en un momento particular de su trayectoria migrante, a saber, el procedimiento para obtener la condición de refugio.

\section{Hacia un marco de interpretación de actitudes}

En aras de facilitar la interpretación de datos, los reactivos fueron agrupados en cuatro grandes bloques. Por trayectorias se entiende la travesía que el migrante ha recorrido desde que sale de su país para trasladarse a México, pasando por un punto fronterizo, hasta el lugar donde se encontraba al momento de la entrevista —reactivos: país de origen, frontera MéxicoGuatemala, México, Tapachula-Tenosique-. Procedimientos y medidas de protección engloba los trámites para solicitar la condición, lo que deviene de dichas diligencias y $\mathrm{CVRH}$-reactivos: solicitar refugio, refugio otorgado, refugio rechazado, visa humanitaria $(\mathrm{CVRH})$ —. Autoridades incluye a diversas autoridades que aparecen en la trayectoria del migrante - reactivos: INM, estación migratoria, Policía Federal, Policía Municipal, Ejército-. (In) seguridad hace alusión a las percepciones relativas a la seguridad —reactivos: ser víctima, no tener papeles, riesgo, inseguridad-. En las tablas 1, 2, 3 y 4 se presentan todas las respuestas de los participantes, agrupadas en los cuatro bloques.

Para la interpretación de los datos se dio un giro al modelo del diferencial semántico (Osgood, Suci y Tannenbaum, 1957), en el cual un concepto adquiere significado cuando un signo - palabra - puede provocar una respuesta que se asocia al objeto que representa, es decir, se reacciona ante el objeto simbolizado (Hernández, Fernández y Baptista, 2014). En la prueba del diferencial semántico se presentan al sujeto una serie de adjetivos en escala que contiene valores intermedios, para relacionarla con el concepto - equivalente al «reactivo»—. En este trabajo se dejó al libre albedrío la reacción al reactivo. Para simplificar la interpretación se optó por dos «valores», positivo y negativo, si bien es cierto que las valoraciones pueden ser diversas - favorables o desfavorables, pesimista, optimista, entre otros- (Worchel et al., 2002).

En las tablas de calificación de actitudes (tablas 1, 2, 3 y 4) la respuesta corresponde a una connotación positiva (+) en la actitud o bien una negativa (-); la ausencia de respuesta o una respuesta no válida se codifica con cero (0). Se utiliza la letra «A» para incluir respuestas en las cuales están presentes 
dos actitudes opuestas, indefinidas o vagas. Dentro de este grupo también se han congregado actitudes que se acercan más a una valoración neutral o indeterminada. Conscientes de que «A» puede considerarse como una zona ambivalente, no se hace uso intencional de una escala medible, sino más bien de una gama de actitudes, en consonancia con el alcance aproximativo de este estudio. Interesa la tendencia posible que se puede inferir de la concentración de réplicas para cada reactivo y cada bloque, no su valor estadístico.

\section{Discusión de los datos}

Al escudriñar los reactivos del bloque trayectorias (véase tabla 1), los datos revelan muchos matices en las actitudes. Los territorios y espacios que forman parte de una travesía migratoria evocan actitudes positivas y negativas, así como algunas neutrales, o de otra índole. Un itinerario migratorio - particularmente en situación no autorizada - se caracteriza por un horizonte de claroscuros: la esperanza de alcanzar un destino seguro que brinde mejores condiciones de vida que el lugar del cual se partió, pero, a la vez, una travesía que presenta muchos peligros potenciales. Por ello las actitudes suelen ser contrastantes, dependiendo de las experiencias en la salida, el tránsito y la llegada a un destino. Pueden ser dos caras de una misma

[188 ] moneda, como sucede a quienes ven tanto algo positivo como algo negativo en su país de origen —Cesar, Saúl—. De manera similar, las percepciones sobre los destinos de las personas pueden resultar contrarias: la visión de Vico es opuesta a la de Rina y a la de Miguel sobre las ciudades donde cada quien solicitó la condición. La trayectoria suele encerrar dos sentimientos en juego o en tensión: por un lado, la esperanza de conseguir protección, de estar a salvo, por otro lado, la carga emocional de lo que se tuvo que dejar atrás y la incertidumbre de lo que está por venir.

No se encontraron en los resultados tendencias contundentes entre salir de una situación de peligro — negativo - a un lugar de seguridad completa - positivo-; es decir, que se esperaría que la totalidad de las respuestas fueran positivas sobre R3 - México-y R4 - Tapachula-Tenosique-. Si bien al hacer la comparación entre todas las respuestas sobre lugar de origen (R1) y lugar de destino (R4) se vislumbra un claro gradiente que va de negativo a positivo, también hay respuestas negativas sobre R3 y R4: violencia, racismo, rechazo — Vico-, muerte — Lobo—, pandillas — Sergio—, no hay trabajo -Chon-. Lo anterior sugiere que no existen las condiciones indispensables para que México sea considerado un país plenamente seguro. 
Oscilar entre la esperanza y la incertidumbre...

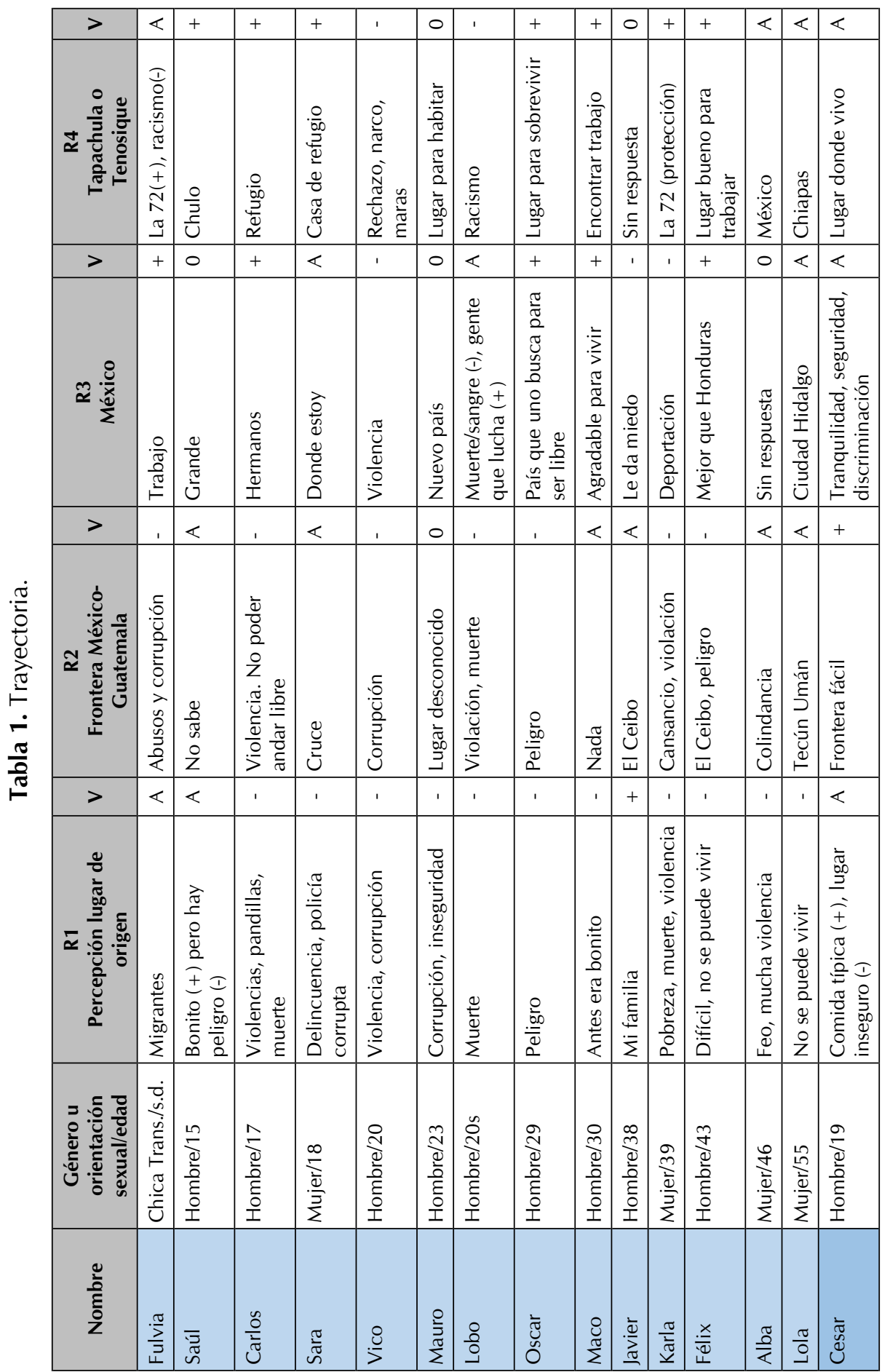

[189] 


\begin{tabular}{|c|c|c|c|c|c|c|c|c|c|c|}
\hline$>$ & + & + & $\ll$ & + & + & + & + & & $\ll$ & \multirow[b]{2}{*}{ 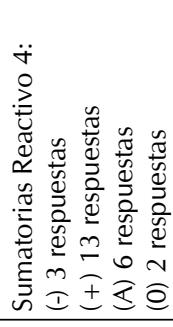 } \\
\hline 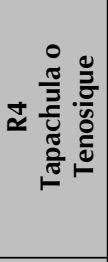 & $\begin{array}{l}\frac{0}{2} \\
\frac{000}{\bar{d}} \\
\frac{0}{<}\end{array}$ & 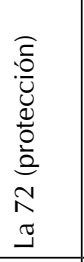 & 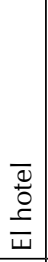 & 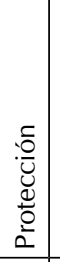 & 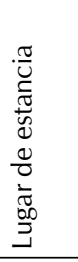 & 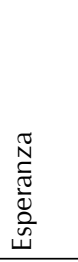 & 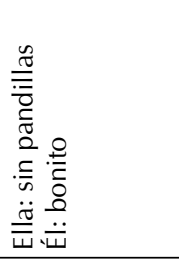 & 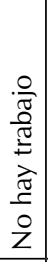 & 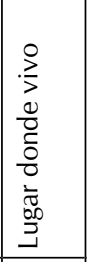 & \\
\hline$>$ & $\ll$ & $\ll$ & 0 & + & + & + & + & 0 & ' & \multirow[b]{2}{*}{ 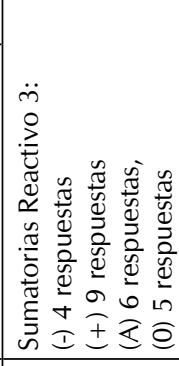 } \\
\hline$\cong \frac{8}{\frac{u}{x}}$ & $\stackrel{\ddot{\circ}}{\dot{0}}$ & 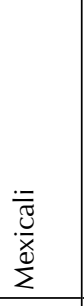 & 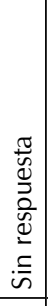 & 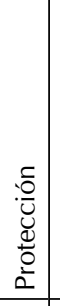 & 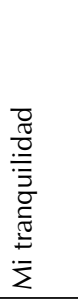 & 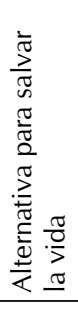 & 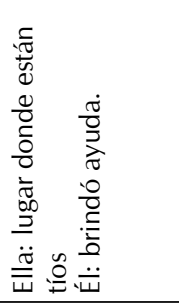 & 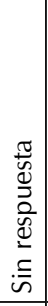 & 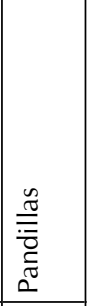 & \\
\hline$>$ & $<$ & . & $\ll$ & 1 & + & $\ll$ & . & $\ll$ & 1 & \multirow[b]{2}{*}{ 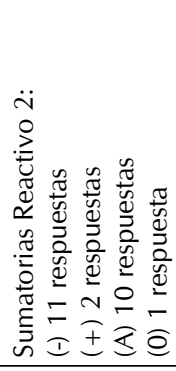 } \\
\hline 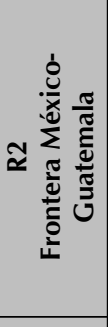 & 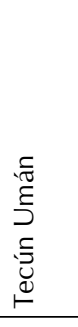 & 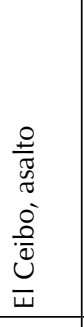 & 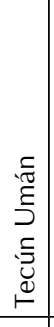 & 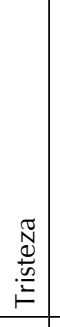 & 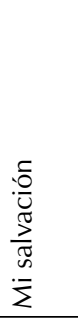 & 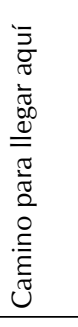 & 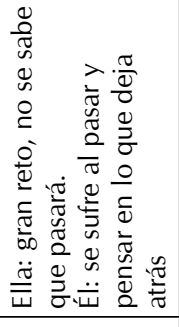 & 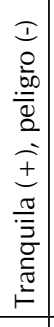 & 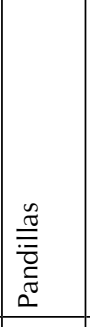 & \\
\hline$>$ & $\ll$ & $\ll$ & ' & $\ll$ & ' & , & ' & + & $\ll$ & \multirow[b]{2}{*}{ 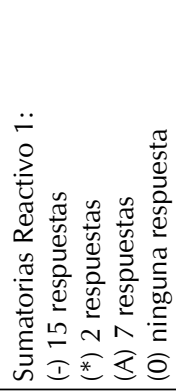 } \\
\hline 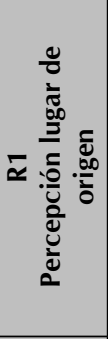 & 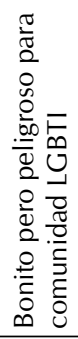 & 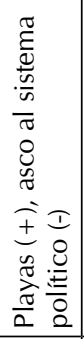 & 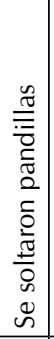 & $\begin{array}{l}0 \\
\stackrel{c}{0} \\
.00 \\
0 \\
0\end{array}$ & 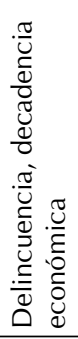 & 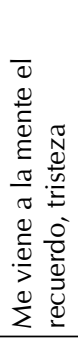 & 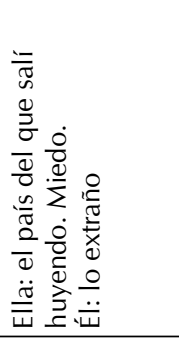 & 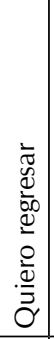 & 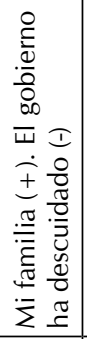 & \\
\hline 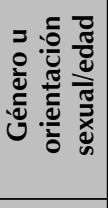 & 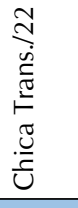 & 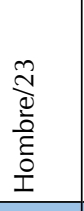 & 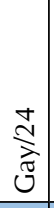 & $\begin{array}{l}m \\
\stackrel{n}{2} \\
\frac{\omega}{\frac{\omega}{3}} \\
\sum\end{array}$ & 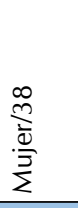 & 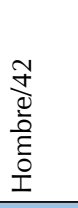 & 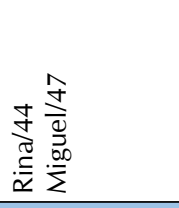 & 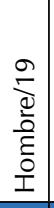 & 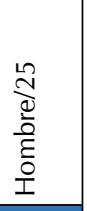 & \\
\hline $\begin{array}{l}0 \\
\frac{0}{E} \\
\text { Zे }\end{array}$ & $\frac{\underline{\sigma}}{\underline{\Xi}}$ & 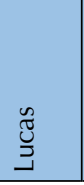 & $\begin{array}{l}0 \\
\frac{0}{0} \\
\text { हे } \\
\text { 인 } \\
\end{array}$ & $\begin{array}{l}\frac{\pi}{\bar{d}} \\
\frac{\pi}{n}\end{array}$ & $\stackrel{\frac{\pi}{2}}{\frac{\pi}{\pi}}$ & $\stackrel{8}{\unlhd}$ & 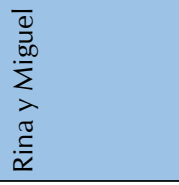 & $\begin{array}{l}\check{\Xi} \\
\text { ปे }\end{array}$ & 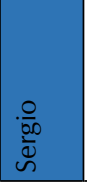 & \\
\hline
\end{tabular}


En el bloque procedimientos y medidas de protección (véase tabla 2) sobresalen las calificaciones positivas. Más de la mitad de los informantes ofrecen respuestas que podrían denominarse optimistas, según lo demuestran las actitudes para R1 y R2. Merece particular atención R3, porque ante la adversidad se encontraron manifestaciones de actitudes proactivas: agarrar el tren — Saúl—, apelar — Sara— o pedir revisión — Maco—, seguir firme Lobo-. Son respuestas de optimismo o resistencia, encarnan la expectativa que albergan los solicitantes con relación a que se les otorgue la condición de refugio.

No obstante, determinadas actitudes requieren de una indagación más detallada: primero, la cantidad de respuestas con 0 sobre la visa humanitaria (R4) es indicativa de que mucha gente no sabía sobre lo que se les preguntaba, desconocían esa medida de protección; segundo, apelar a la intervención divina —Vico: seguir orando; Julia: «iJesucristo!»; Chon: en las manos de Dios- abre interrogantes que no se pueden resolver a entera satisfacción: ¿hay resignación o confianza depositada en una fuerza superior que todo lo puede?, ¿la actitud se concibe más allá de cualquier esperanza posible o es una manera de racionalizar que algo bueno pueda acontecer?, ¿se trata de un recurso para lidiar con el trauma y la penuria (Lusk et al., 2019)? El designio divino puede significar optimismo, pero resignarse a esa fuerza suprema también puede interpretarse como una actitud conformista, por ello se le atribuye simultáneamente una carga positiva y una negativa.

Dentro de todo el espectro de actitudes, el bloque autoridades (véase tabla 3) contiene el mayor número de respuestas con carga negativa. Muchos informantes fueron categóricos en su actitud de rechazo hacia diferentes representantes de la autoridad; algunos sustentaban actitudes mixtas, es decir, simpatía hacia ciertos cuerpos de seguridad, pero repulsa para otros - Sara, Oscar, Lucas_; solo Javier y Leo calificaron favorablemente a todas las autoridades. No obstante, es necesario señalar la existencia de actitudes neutrales. Ejemplo: Reactivo: agente de INM. Respuesta: Ni mal ni bien -Félix - La ambigüedad en las respuestas de Félix - y Lola - también puede ser interpretada como un desconocimiento sobre las funciones de cada corporación. 


\begin{tabular}{|c|c|c|c|c|c|c|c|c|c|c|c|c|c|}
\hline$>$ & ' & 0 & ' & 0 & 0 & 0 & ' & + & + & 0 & 0 & $\ll$ & ' \\
\hline ¿ & 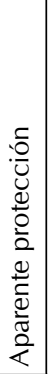 & 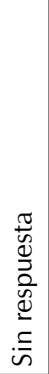 & 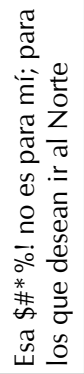 & 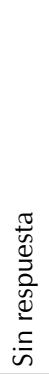 & 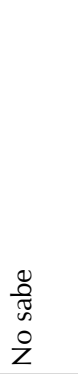 & 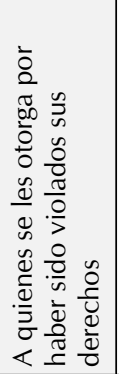 & 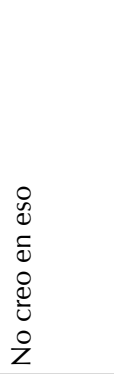 & 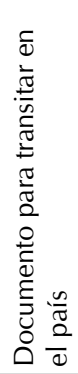 & 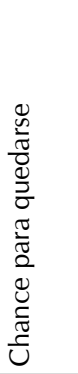 & 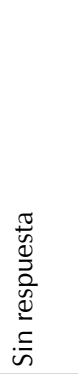 & 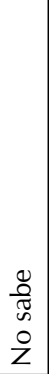 & 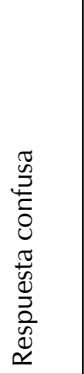 & : \\
\hline$>$ & ' & + & ' & + & + & 0 & + & ' & + & T & + & 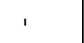 & 0 \\
\hline 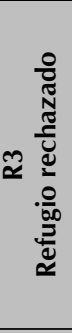 & 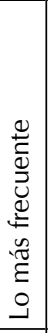 & 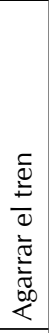 & 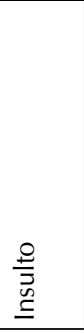 & $\begin{array}{l}\frac{\pi}{0} \\
\frac{0}{2}\end{array}$ & 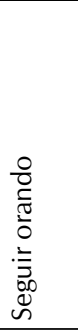 & 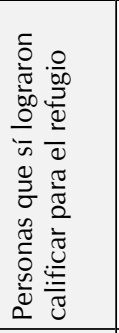 & 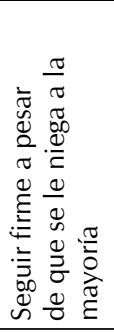 & 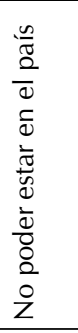 & $\begin{array}{l}: 0 \\
: \frac{0}{2} \\
\frac{0}{2} \\
: \overline{0} \\
0 \\
0\end{array}$ & 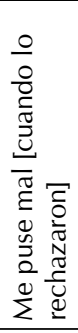 & 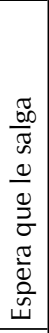 & 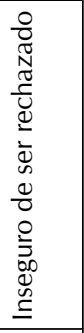 & 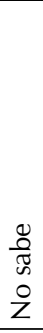 \\
\hline$>$ & ' & + & + & + & ' & 0 & ' & + & + & + & + & $\ll$ & + \\
\hline 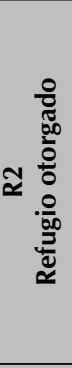 & 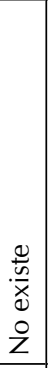 & 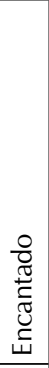 & 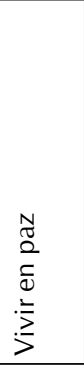 & 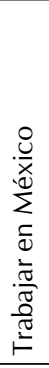 & 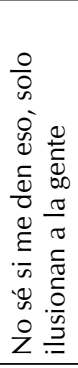 & 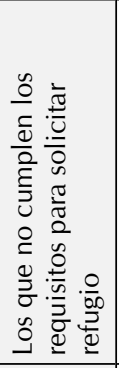 & 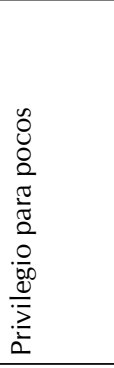 & 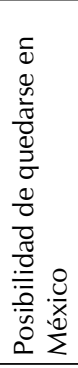 & 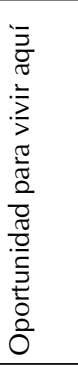 & 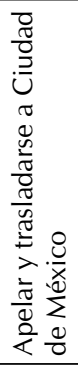 & 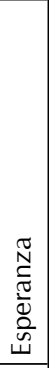 & 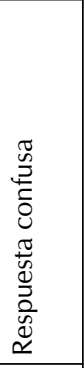 & $\frac{\circ}{\frac{\sqrt{3}}{<}}$ \\
\hline$>$ & ' & + & + & + & ' & 0 & , & + & + & $<$ & 0 & $\ll$ & + \\
\hline 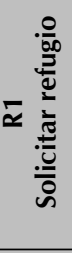 & 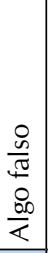 & $i$ & 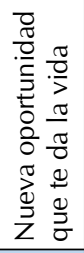 & 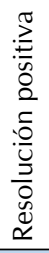 & 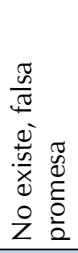 & 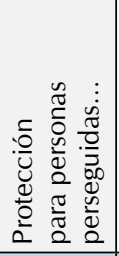 & 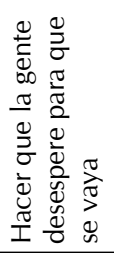 & 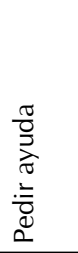 & 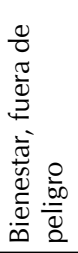 & 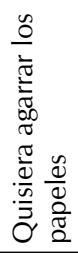 & 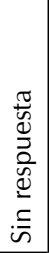 & 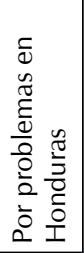 & 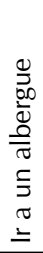 \\
\hline 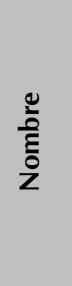 & 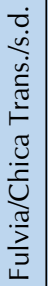 & 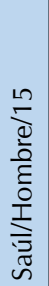 & 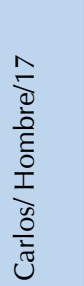 & 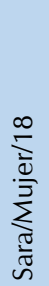 & 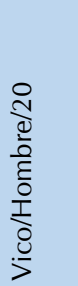 & 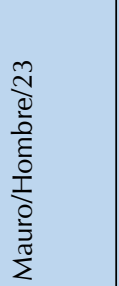 & 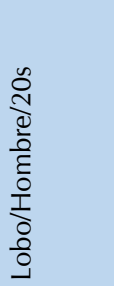 & 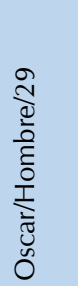 & 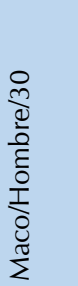 & 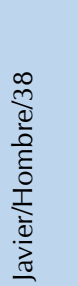 & 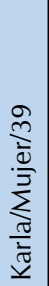 & 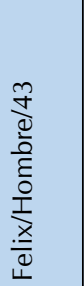 & 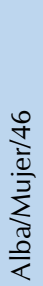 \\
\hline
\end{tabular}


Oscilar entre la esperanza y la incertidumbre...

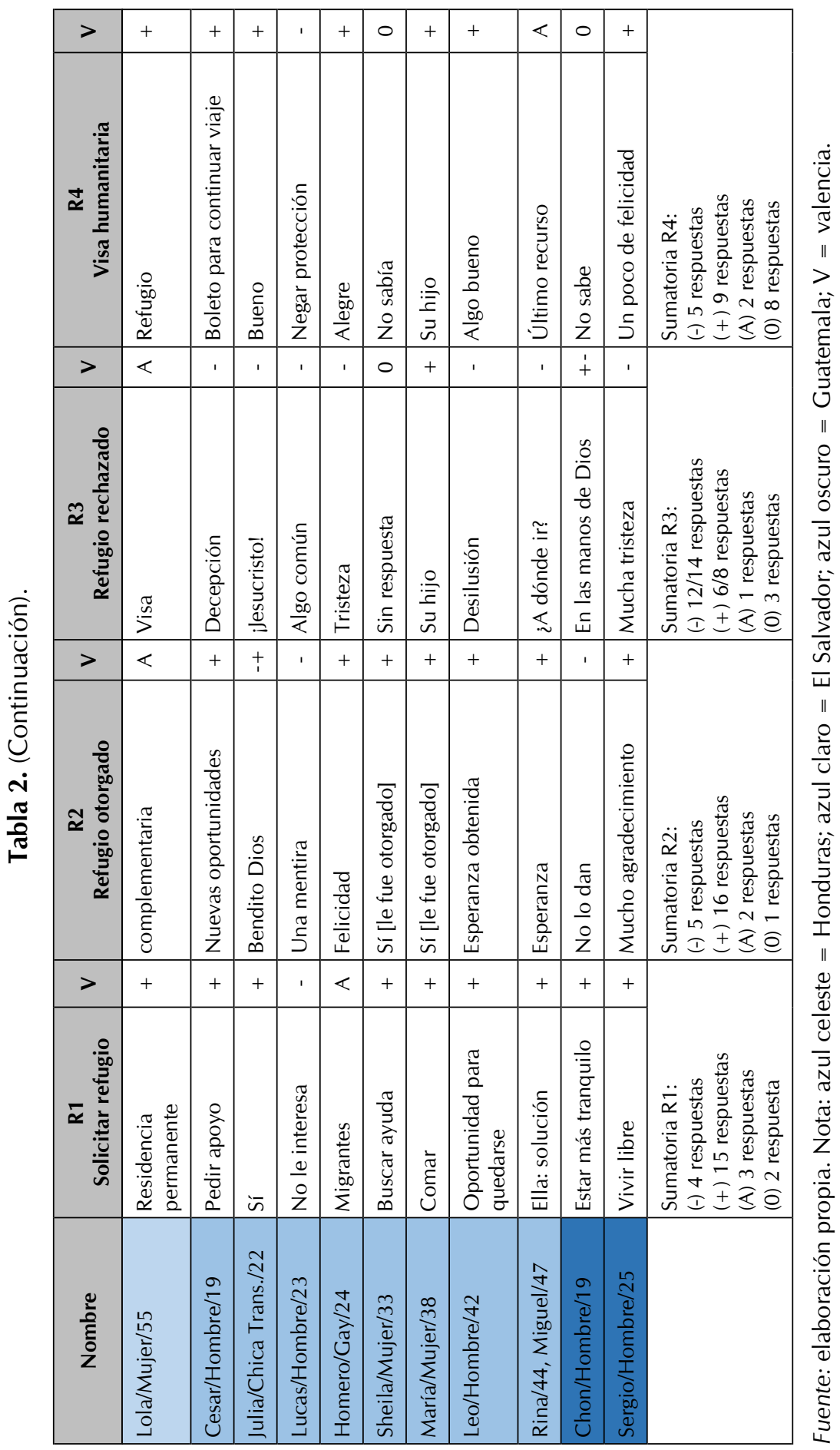




\begin{tabular}{|c|c|c|c|c|c|c|c|c|c|c|c|c|c|c|c|}
\hline$>$ & ' & ' & ' & + & 0 & 0 & ' & ' & ' & + & ' & 0 & $<$ & $\ll$ & $\ll$ \\
\hline 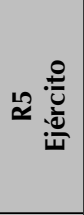 & 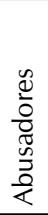 & 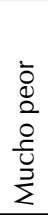 & 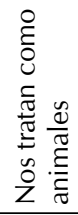 & $\begin{array}{l}0 \\
\frac{1}{0} \\
\frac{0}{0} \\
\frac{0}{2} \\
\frac{0}{2}\end{array}$ & 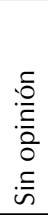 & 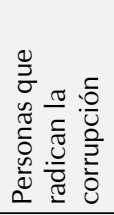 & $\begin{array}{l}\frac{n}{0} \\
\frac{0}{0} \\
\frac{0}{0} \\
>\end{array}$ & 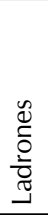 & 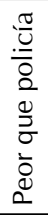 & $\begin{array}{l}\stackrel{0}{0} \\
\stackrel{0}{0} \\
\stackrel{0}{D}\end{array}$ & 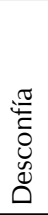 & 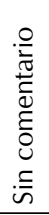 & $\frac{\sigma}{\overline{\frac{\pi}{\pi}}}$ & $\begin{array}{l}\overline{\frac{\pi}{2}} \\
\frac{\pi}{8} \\
1\end{array}$ & $\begin{array}{l}\frac{7}{0} \\
\frac{0}{0} \\
\frac{0}{2} \\
\frac{1}{3} \\
\end{array}$ \\
\hline$>$ & I & 0 & 1 & $\ll$ & ' & 0 & 1 & + & 0 & + & 1 & 0 & $<$ & $<$ & ' \\
\hline 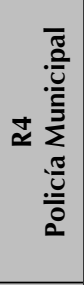 & 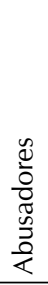 & 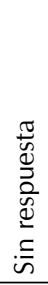 & 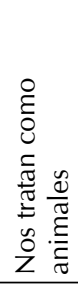 & $\begin{array}{l}\cdot \frac{0}{2} \\
\frac{\sqrt{2}}{\frac{1}{5}} \\
\frac{3}{2}\end{array}$ & $\begin{array}{l}\frac{n}{2} \\
\frac{2}{2} \\
0 \\
0\end{array}$ & 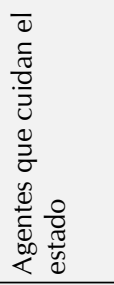 & 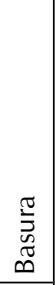 & $\begin{array}{l}\frac{\pi}{c} \\
\frac{0}{0} \\
\frac{0}{0} \\
\frac{0}{n} \\
\frac{5}{n}\end{array}$ & 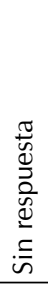 & 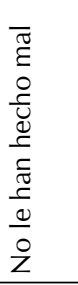 & 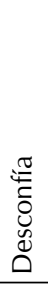 & 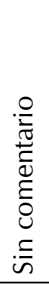 & 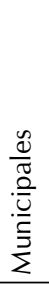 & 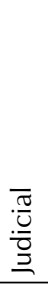 & 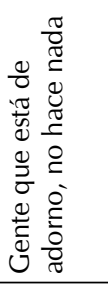 \\
\hline$>$ & , & , & , & + & , & 0 & 1 & 1 & 0 & + & . & $\ll$ & $\ll$ & $\ll$ & $\ll$ \\
\hline 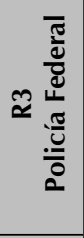 & 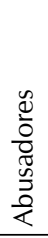 & ż & 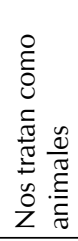 & 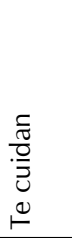 & $\begin{array}{l}0 \\
0 \\
\frac{0}{0} \\
\frac{0}{0} \\
0 \\
0 \\
\frac{2}{2}\end{array}$ & 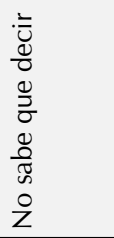 & $\begin{array}{l}\frac{n}{0} \\
\frac{0}{0} \\
\frac{0}{0} \\
\frac{0}{0} \\
>\end{array}$ & $\begin{array}{l}\stackrel{\mathscr{U}}{0} \\
\frac{0}{0} \\
\frac{0}{J}\end{array}$ & 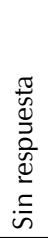 & 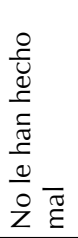 & 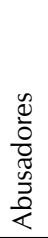 & $\begin{array}{l}\frac{\bar{d}}{0} \\
\frac{\bar{a}}{\bar{\theta}} \\
\frac{\varepsilon}{\bar{Z}}\end{array}$ & 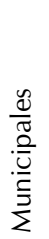 & 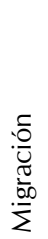 & $\begin{array}{l}\frac{0}{\pi} \\
\frac{\pi}{0} \\
\frac{0}{2} \\
\frac{1}{2}\end{array}$ \\
\hline$>$ & 1 & 0 & 1 & + & 1 & 0 & 1 & $\ll$ & 0 & 1 & , & + & $\ll$ & $\ll$ & 0 \\
\hline 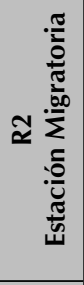 & $\frac{0}{0}$ & 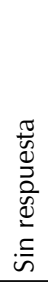 & 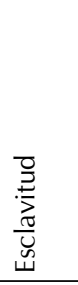 & 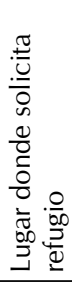 & 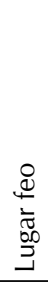 & 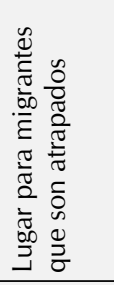 & 离 & 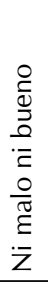 & 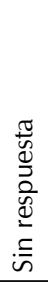 & 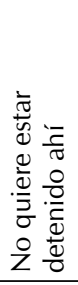 & 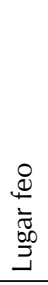 & $\begin{array}{l}\frac{1}{0} \\
\frac{0}{0} \\
0 \\
0 \\
0 \\
-\end{array}$ & $\frac{\bar{\pi}}{i \frac{00}{2}}$ & $\frac{\pi}{\frac{\pi}{U}}$ & 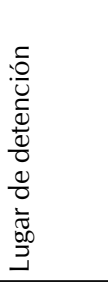 \\
\hline$>$ & 1 & 1 & 1 & 1 & 1 & 0 & 1 & $\ll$ & 0 & + & 1 & $<$ & 0 & $\ll$ & 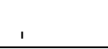 \\
\hline 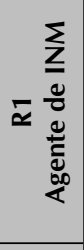 & $\begin{array}{l}\frac{0}{0} \\
\frac{0}{0} \\
\frac{\pi}{0} \\
\frac{0}{7}\end{array}$ & $\frac{\frac{0}{0}}{\stackrel{0}{2}}$ & 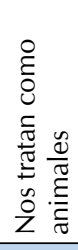 & 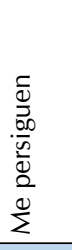 & $\begin{array}{l}\frac{1}{0} \\
\frac{0}{2} \\
\frac{2}{2} \\
0 \\
0\end{array}$ & 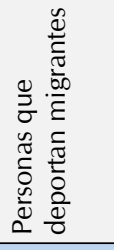 & 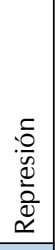 & $\begin{array}{l}\frac{n}{0} \\
\frac{\pi}{E} \\
\lambda \\
\tilde{0} \\
0 \\
\frac{0}{0} \\
0 \\
0\end{array}$ & 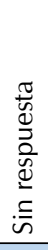 & $\frac{\frac{\pi}{\pi}}{\frac{0}{2}}$ & 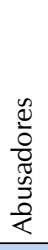 & 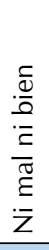 & 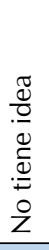 & $\frac{\pi}{\frac{\pi}{0}}$ & 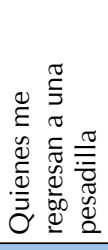 \\
\hline 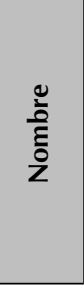 & 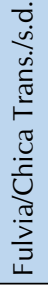 & 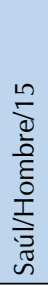 & 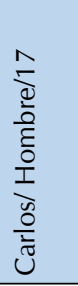 & 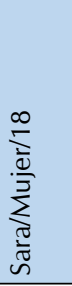 & 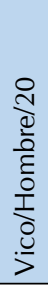 & 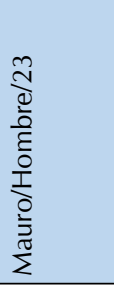 & 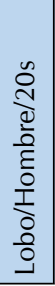 & 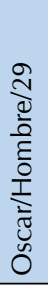 & 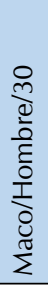 & 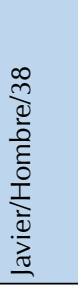 & 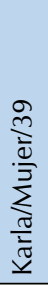 & 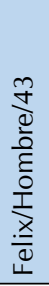 & 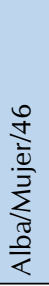 & 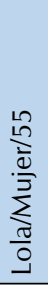 & 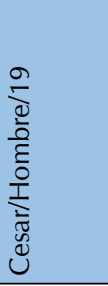 \\
\hline
\end{tabular}


Oscilar entre la esperanza y la incertidumbre...

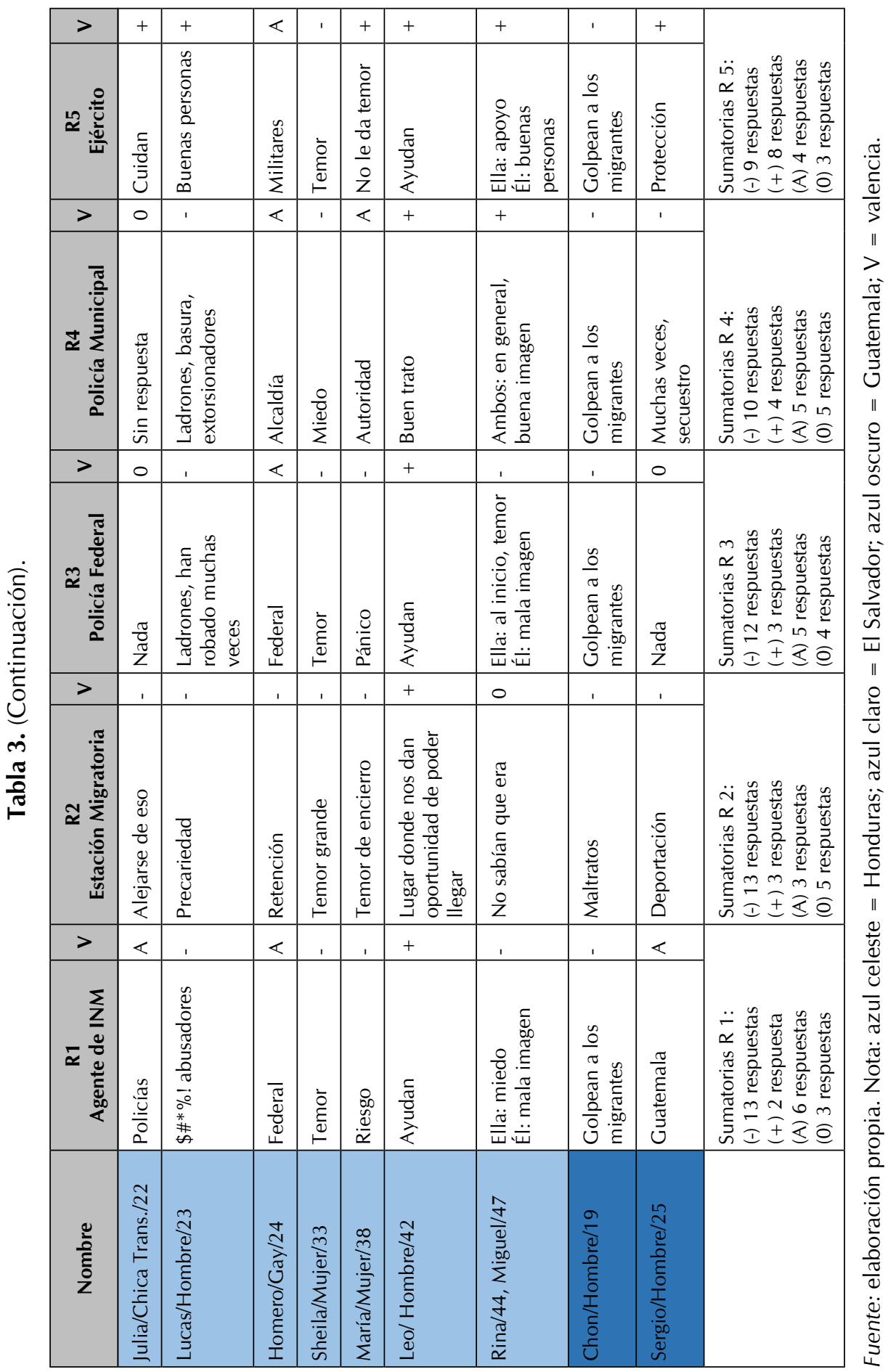

[195] 
Las autoridades con menos reacciones negativas fueron los elementos castrenses. Uno de cada tres informantes calificó en forma positiva a los militares, resultado afín a lo reportado por Ramos, Coraza y Martínez (2018, pp. 67-68). La actitud positiva puede estar ligada a la percepción de que las fuerzas armadas son menos susceptibles de corrupción que otras autoridades mexicanas (para una opinión contraria, véase WOLA, 2017, noviembre). Los centroamericanos llegan de países en los cuales la represión policial y la militarización de la vida en sociedad han desempeñado un papel importante en la historia reciente. Obviamente, las actitudes también se formarán en función del contacto directo con los representantes del Gobierno mexicano, en algunos casos son favorables, en otros no.

Indiscutiblemente la connotación negativa más fuerte se concentra en los reactivos del bloque (in)seguridad (véase tabla 4). La inseguridad tiene que ver con experiencias dolorosas que motivaron la huida. También está asociada a la condición no autorizada en la que llegan los solicitantes a México, la cual los hace enfrentar situaciones de precariedad. A la vez, refleja la incertidumbre que experimentan quienes esperan una resolución a su petición de refugio. En este punto es necesaria una explicación. No hay manera de escapar a la carga negativa, inherente al sentido común, asociado a los reactivos «inseguridad», «no tener papeles», «ser víctima». En esta investigación se carece de una salida metodológica para justificar que la respuesta emocional esperada que se les otorga a estos reactivos sea, en consecuencia, negativa. Establecido lo anterior, se arriesga aquí el introducir un sesgo al trabajo, pero sin prejuicio alguno. Justamente para detectar formas de pensamiento disidentes a lo que se asume y designa como naturalmente negativo y adverso, resultó útil e importante que aparecieran en las respuestas valores indeterminados, e incluso positivos, a reactivos que son contrarios a la razón. Por ello se observa que ciertas respuestas de Sara, Lobo y Julia toman particular significancia para vislumbrar algo así como un posicionamiento político de resistencia, no obstante que ese discurso es atenuado por las limitaciones y las condiciones materiales que enfrentan los propios sujetos.

Hay muy poca ambigüedad en las respuestas a este bloque, ya que la gente está consciente de la difícil realidad que enfrenta, de encontrarse inestables y prácticamente indefensos. Reactivo: «inseguridad». Respuestas: nadie ayuda, a nadie le importa — Vico—; vivir con miedo, en peligro —Carlos-; no tengo papeles, no tengo nada -Félix-. 
Oscilar entre la esperanza y la incertidumbre...

\begin{tabular}{|c|c|c|c|c|c|c|c|}
\hline$>$ & ' & 0 & ' & ' & ' & 0 & ' \\
\hline 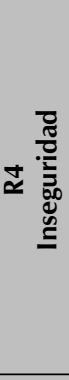 & 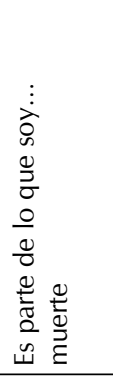 & 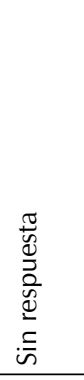 & 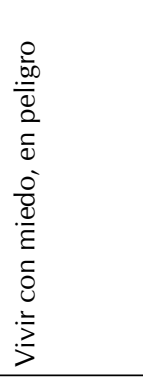 & $\begin{array}{l}\frac{0}{0} \\
\frac{\pi}{\omega} \\
\frac{\omega}{\pi} \\
\frac{0}{0} \\
心 \\
0 \\
\frac{\omega}{\pi} \\
\frac{2}{\pi} \\
\end{array}$ & 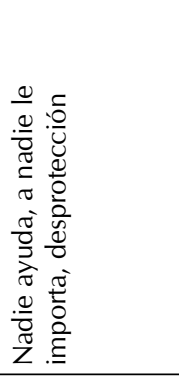 & 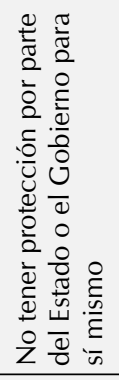 & 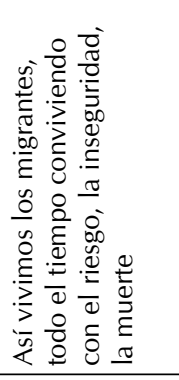 \\
\hline$>$ & ' & ' & ' & $\ll$ & ' & 0 & + \\
\hline ※ & 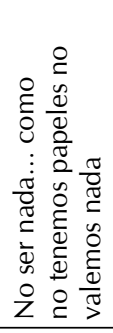 & 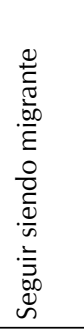 & 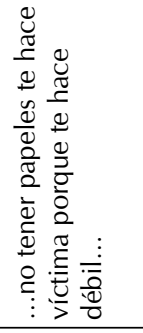 & $\frac{\widetilde{\varpi}}{\infty}$ & 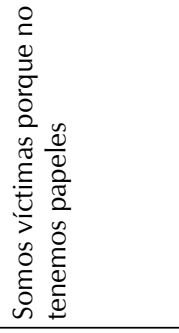 & 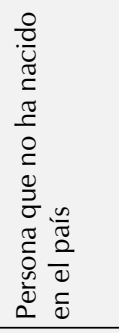 & 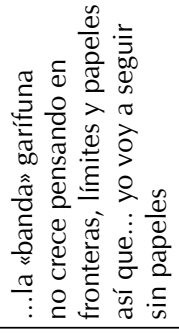 \\
\hline$>$ & ' & ' & ' & 1 & 1 & 0 & 1 \\
\hline$\approx \underset{\frac{d}{\alpha}}{\stackrel{\infty}{\alpha}}$ & 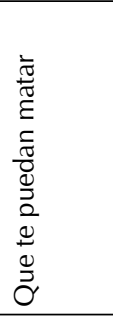 & 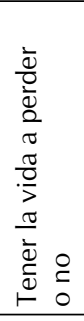 & 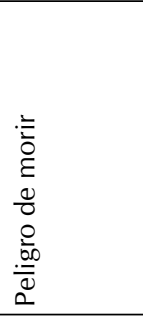 & 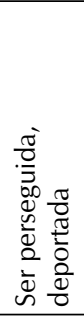 & 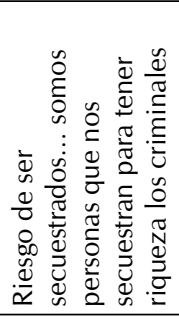 & 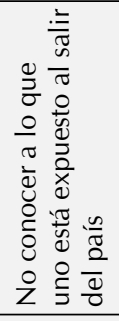 & 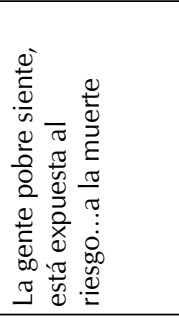 \\
\hline$>$ & 1 & 1 & 1 & + & ' & 0 & i \\
\hline 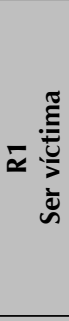 & 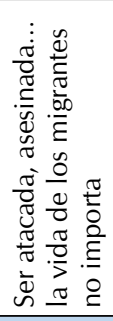 & $\begin{array}{l}\stackrel{\otimes}{\Perp} \\
ٍ \\
\sum\end{array}$ & 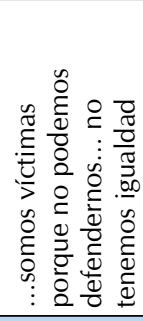 & 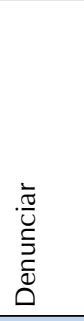 & 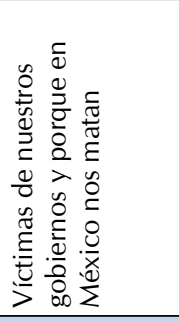 & 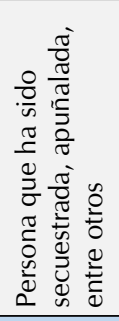 & 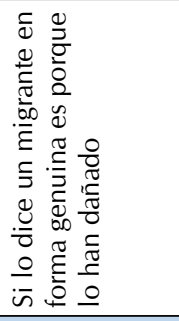 \\
\hline $\begin{array}{l}\text { ڤँ } \\
\text { है } \\
\text { Zे }\end{array}$ & 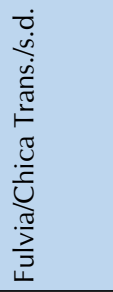 & 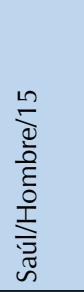 & 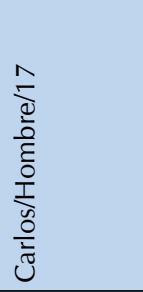 & 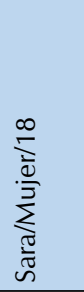 & 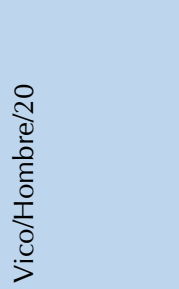 & 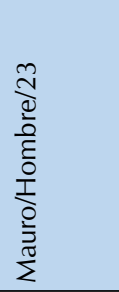 & 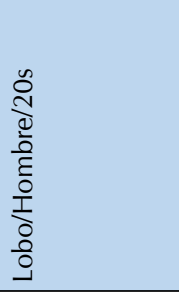 \\
\hline
\end{tabular}




\begin{tabular}{|c|c|c|c|c|c|c|c|c|c|c|}
\hline$>$ & ' & ' & ' & ' & ' & 0 & ' & ' & 0 & ' \\
\hline 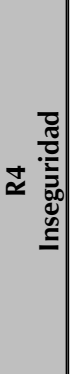 & 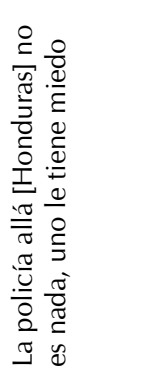 & 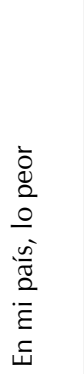 & 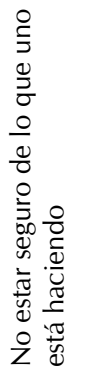 & 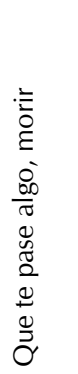 & 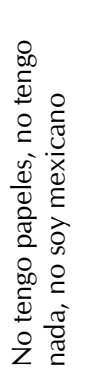 & $\begin{array}{l}\text { o } \\
\text { ज़ } \\
0 \\
\text { Z }\end{array}$ & 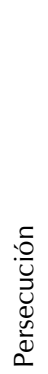 & 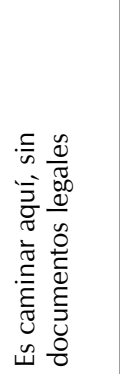 & 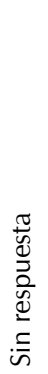 & 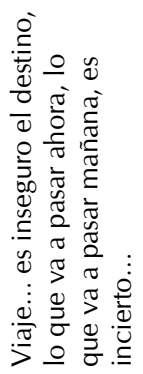 \\
\hline$>$ & I & $<$ & 1 & I & I & ' & I & $<$ & + & ' \\
\hline 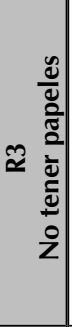 & $\begin{array}{l}\frac{n}{0} \\
\frac{0}{2} \\
2 \\
0 \\
\frac{0}{0} \\
\frac{0}{0} \\
\frac{0}{0} \\
\frac{0}{0} \\
0 \\
0 \\
0 \\
0\end{array}$ & 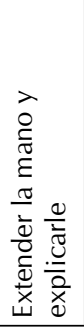 & 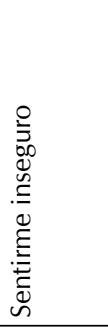 & 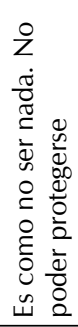 & 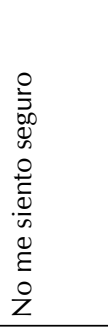 & 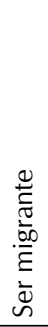 & 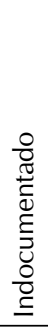 & 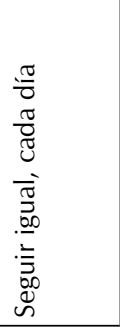 & 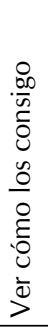 & 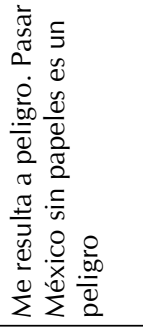 \\
\hline$>$ & ' & 0 & 1 & ' & $\ll$ & ' & ' & ' & ' & ' \\
\hline 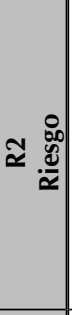 & 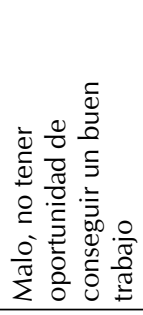 & 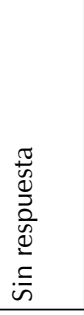 & 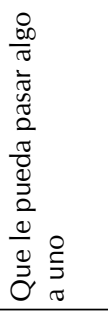 & 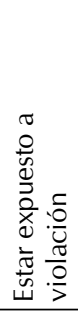 & 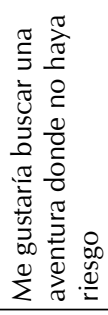 & $\begin{array}{l}\frac{\pi}{0} \\
\frac{\pi}{0} \\
\frac{0}{2} \\
0 \\
0 \\
0 \\
\frac{\pi}{0} \\
\frac{0}{2} \\
\frac{0}{0} \\
0 \\
0 \\
0\end{array}$ & $\begin{array}{l}\frac{0}{00} \\
\frac{.00}{0} \\
0\end{array}$ & 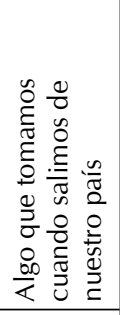 & 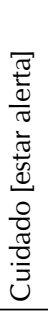 & 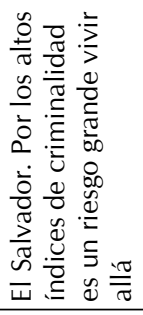 \\
\hline$>$ & $\ll$ & ' & 1 & 1 & 1 & ' & ' & 1 & 1 & 1 \\
\hline 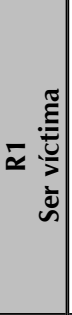 & 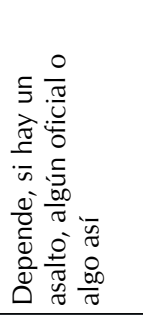 & 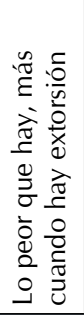 & 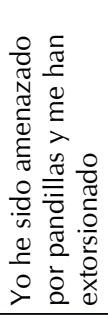 & 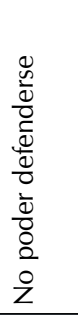 & 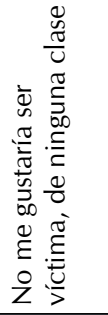 & 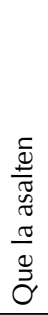 & $\begin{array}{l}\frac{\pi}{\frac{\pi}{\sigma}} \\
\frac{\pi}{\frac{\pi}{5}} \\
\end{array}$ & $\begin{array}{l}\frac{\overline{0}}{\pi} \\
\frac{\pi}{0} \\
0 \\
\frac{00}{\pi} \\
\frac{\pi}{2} \\
\frac{1}{2} \\
\frac{0}{0} \\
0 \\
0 \\
\end{array}$ & $\begin{array}{l}\frac{0}{2} \\
\frac{\pi}{\pi} \\
\frac{\pi}{0}\end{array}$ & 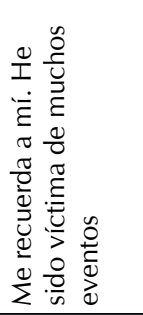 \\
\hline $\begin{array}{l}\text { गे } \\
\text { है } \\
\text { Z }\end{array}$ & 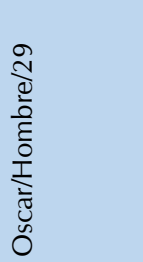 & 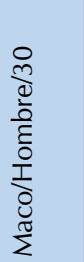 & 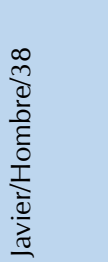 & 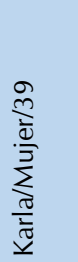 & 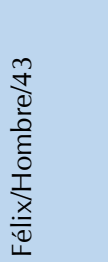 & 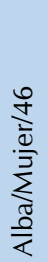 & 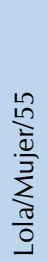 & 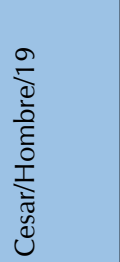 & 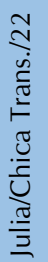 & 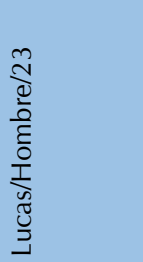 \\
\hline
\end{tabular}


Oscilar entre la esperanza y la incertidumbre...

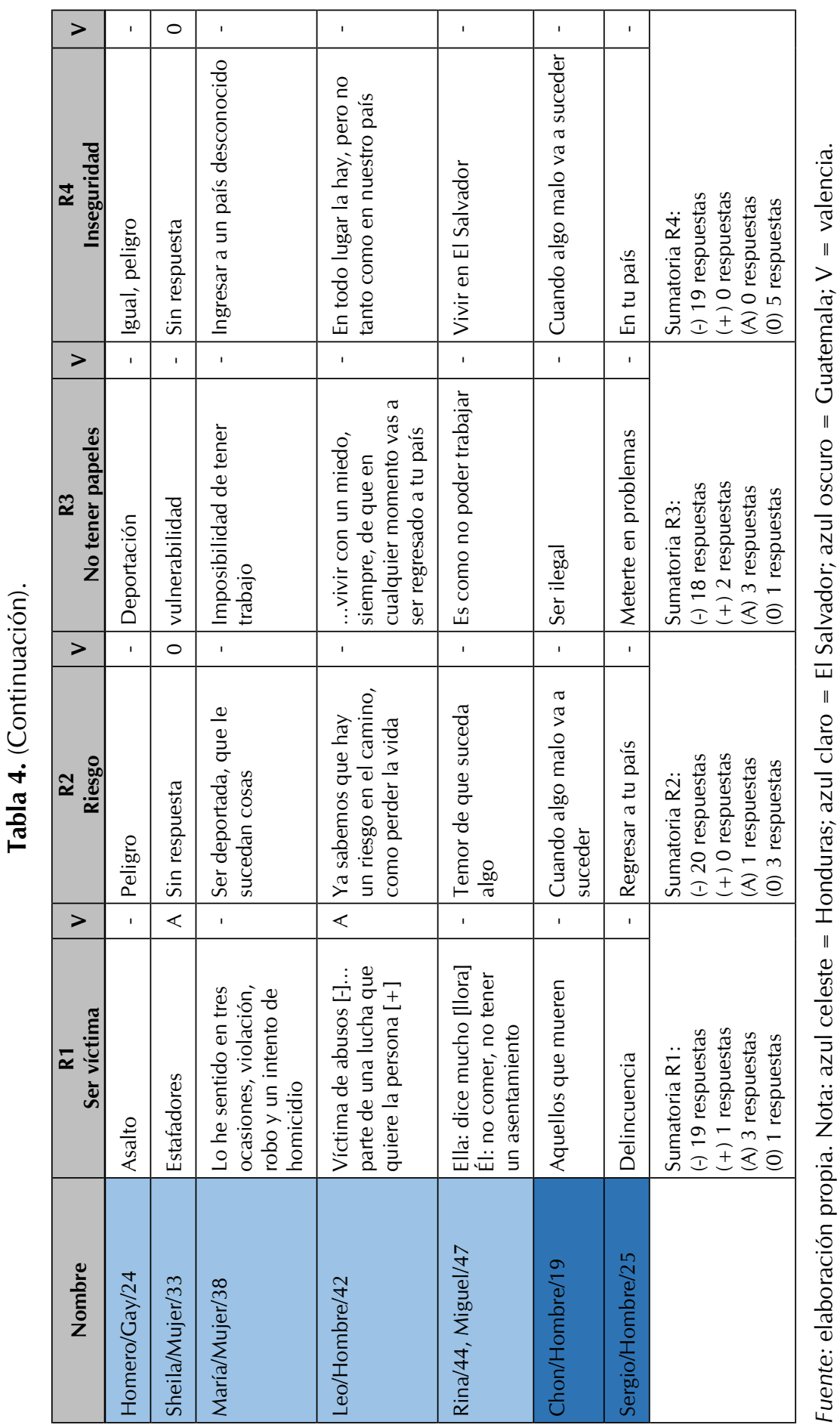

[199] 
Incluso obtener la condición no garantiza un mínimo de seguridad porque hay factores estructurales y culturales adversos, tales como la falta de acceso a trabajo digno, escaso apoyo gubernamental y el rechazo, xenofobia y discriminación de que son objeto los centroamericanos en Tapachula y Tenosique. Otro factor en contra para alcanzar la seguridad plena es la presencia de Maras en México. La inseguridad imbrica y concentra toda la experiencia de un migrante que solicita la condición de refugiado, desde lo que acaece en su viaje, pasando por enfrentarse a las autoridades, hasta el resultado al procedimiento. Las actitudes se refuerzan y ligan unas a otras. Se puede llegar a ser víctima por estar en riesgo, a su vez, sinónimo de inseguridad. Es no existir. Reactivo: no tener papeles. Respuestas: no somos nada porque no tenemos papeles... como nosotros los migrantes no tenemos papeles, no valemos nada... no existimos —Fulvia—; es como no ser nada —Karla(Green, 2011). Este panorama es reflejo de una condición de vida, sobre el pasado - trayectoria peligrosa-, el presente — la esperanza de obtener protección, enfrentar autoridades, nuevo país, entre otros- $-y$, hasta cierto punto, el futuro —incertidumbre, protección nominal, seguridad endeble-.

Se plantea aquí la tesis de que quienes no dieron respuesta al reactivo «inseguridad» fue porque esa era su forma de autoprotección, incluso de evasión, para no pensar en un desenlace indeseado. El caso de Mauro resulta paradigmático. En sus respuestas para todos los bloques el entrevistado define los reactivos, pero no los califica. No habla de sus percepciones emotivas o sensoriales. Él organiza sus respuestas de tal manera que pareciera que hay un «rompimiento» entre sus emociones y su pensamiento, con un control volitivo de la parte racional sobre la parte emocional, a manera de esquiva.

Allende las connotaciones positivas asociadas a los procedimientos para solicitar medidas de protección y las cargas negativas que puedan vincularse a la trayectoria, las experiencias de inseguridad o a las autoridades en México, hay individuos que muestran actitudes no-pasivas y con ello manifiestan CA. Se presentan primero las respuestas que dan cuenta explícita de una proyección de capacidad agentiva, para luego interpretar con detenimiento las réplicas amplias que dio a los reactivos un solicitante de la condición.

- Reactivo: refugio rechazado. Respuesta: agarrar el tren —Saúl一.

- Reactivo: ser víctima. Respuesta: denunciar —Sara-.

- Reactivo: no tener papeles. Respuesta: seguir [migrando] sin papeles Lobo-; ver cómo los consigo — Julia-. 
Lobo, hondureño, del pueblo garinagu, quien no reveló su edad, es el exponente más sobresaliente del migrante que intenta mostrar su CA a través de actitudes que confrontan e interpelan un discurso normalizado en el mundo de las organizaciones sociales, de los organismos internacionales y de la propia academia. Como parte de esa narrativa naturalizada, muchos migrantes son vistos, en general, como víctimas de sus propias circunstancias porque se les considera inherentemente indefensos. Sin embargo, Lobo no asume esa actitud. Sus respuestas a la posibilidad de obtener o no la condición (véanse tablas 1 y 2 ) muestran que inyecta a su actitud una capacidad agentiva potencial. Él va un paso más allá e interpela con sus respuestas la construcción simple de actitudes — positivo o negativo- y del significado de nociones que se dan por sentadas, de la construcción de ese otro. Las siguientes citas textuales proyectan su percepción contestataria sobre México y la noción de víctima:

Entrevistadora: ¿Qué se le viene a la mente cuando le digo México?

Lobo: [...] en Honduras yo solo era mano de obra barata, por ser negro y pobre. Y también era esa persona a la que le puedes quitar lo poco que tiene, su tierra. $\mathrm{Y}$ bueno, a un hombre negro y pobre solo le queda salir, solo le queda eso y claro, como es negro y pobre no tiene opciones. La opción más cercana es México, en donde también va a ser eso, un hombre negro y pobre que nadie quiere, a quien fácilmente puedes matar, porque solo es mano de obra barata, eso es. Es así para nosotros, nuestras opciones son tan limitadas [...]. Es muy feo porque estamos atrapados [...], así vivimos, atrapados, conviviendo con la muerte todos los días, entre México y Centroamérica. Pero así es si eres pobre en este sistema [...] (comunicación personal, Tenosique, 19 de agosto, 2017).

La cita revela a un interlocutor consciente de la situación que vive, del sistema imperante que lo inmoviliza y coloca en limbo — «así vivimos, atrapados»—, y que lo orilla a la inseguridad — «conviviendo con la muerte»—. En términos marxistas diríamos que tiene conciencia de clase y, por otra parte, conciencia identitaria por ser miembro de un grupo discriminado. Aunque su capacidad de respuesta agentiva es neutralizada por el peso del sello securitario en torno al tema migratorio por las condiciones del contexto en el cual pide refugio —discriminación, poco apoyo gubernamental- y, hasta cierto punto, por el proceso mismo — lo prolongado del trámite, pausas que inmovilizan—, él mantiene una firme actitud combativa, ciertamente politizada. 
Entrevistadora: Bien Lobo, y sobre el hecho de ser víctima, ¿qué opina? Lobo: Bueno, es parte de lo mismo, si lo dice un migrante es genuino y bueno, te lo está diciendo porque lo han dañado y eso le duele. También existen otros migrantes que lo utilizan para ganar dinero o algo, pero quiero pensar que la mayoría somos sinceros cuando decimos que hemos sido víctimas en nuestros países o en el camino, igual, los elevaditos de [organismo internacional], no saben de qué hablan y nos hacen ellos víctimas, para mantener su rollo, ya sabes [...] (comunicación personal, Tenosique, 19 de agosto, 2017).

En esta parte Lobo da a entender que existe la posibilidad de una manipulación del discurso o el uso avieso de la narrativa de victimización —riesgo, vulnerabilidad- (Mainwaring, 2016). Categorizar en forma acrítica a los migrantes en su papel de víctimas es estigmatizar a las personas como intrínsecamente vulnerables, para enfatizar la diferencia del otro, es asignar ciertas formas de comportamiento a una de esas etiquetas (Brown, 2011, p. 316), lo cual puede tener como resultado una mayor exclusión de esos migrantes y, hasta cierto punto, una manera de despolitizarlos. La interpelación que hace Lobo llama al replanteamiento de un léxico que se asume de manera convencional, pero que debe ser objeto de cuestionamiento.

\section{[202] Conclusiones}

Gran parte de la experiencia migratoria en la búsqueda de la condición de refugiado en México deviene en un proceso muy adverso para los centroamericanos que lo viven. Así, hay muchas más respuestas categóricas sobre actitudes negativas y menos positivas. También las hay replicas ambivalentes que no pueden plantearse en forma tajante, como es el caso de las trayectorias.

La comprensión de las percepciones y actitudes contribuye al análisis de cómo los solicitantes de refugio centroamericanos conceptualizan y comunican su visión del mundo circundante desde su particular posición. La manera en que conciben su propio país, la percepción del lugar en el que se encuentran en un momento específico de su travesía, su imaginario del destino deseado o planeado, la visión de las autoridades y de su experiencia con los procedimientos y el acceso a medidas de protección puede ser útil para entender mejor la forma en que ellos se relacionan entre sí, con la sociedad a la que llegan y con los servidores públicos. Si bien existe el anhelo de rehacer 
una vida, predomina la sensación de incertidumbre generalizada. Por las razones ya expuestas la seguridad integral que un refugiado debería esperar es exigua en el mejor de los casos. Por ello se habla de indeterminación, precariedad e (in)seguridad. En consecuencia, resulta difícil considerar que en el sur de México existan las condiciones adecuadas de seguridad y acogida para la eventual integración de estos refugiados.

Las respuestas psicológicas de un ser humano ante el infortunio pueden ser negativas —manifestándose en estrés postraumático, reacción psicológica angustiante-, neutrales — resiliencia — o positivas — activación de habilidad para enfrentar la adversidad-. La persona puede pasar de un estado a otro al transcurrir los días o quedar «suspendida» más tiempo en alguna de las primeras dos condiciones. Por ello, todo recurso cognitivo, emocional y psicológico es importante para superar un hecho adverso, para salir de él hacerle frente- - La capacidad agentiva (CA), específicamente, desempeña un papel fundamental para no quedarse instalado en el sufrimiento, en el dolor, en la incertidumbre.

Aunque la CA se ve coartada por factores estructurales - como el régimen securitario que prevalece en el país- y otros que representan limitaciones reales, pero que podrían ser superados, por ejemplo, el limitado conocimiento sobre las medidas de protección con el que arriban los potenciales solicitantes de la condición a México, existen personas como Lobo, Saúl y Sara que no se muestran impasibles ante la adversidad o resignados a un posible resultado desfavorable, a saber, el rechazo de la condición. Algunos, como Lobo, tienen claro que no necesitan ser «rescatados» para representar el papel de víctima que puede llegar a vincularse con la figura del refugiado. Aunque ciertas actitudes transmiten algo que asemeja un posicionamiento político, la cruda realidad es que su alcance real resulta prácticamente nulo. La resistencia está limitada al plano meramente discursivo por las condiciones objetivas en las que se encuentran los solicitantes. En un entorno adverso siempre existe la posibilidad de ir re-ajustando el potencial de CA y la viabilidad de esa capacidad agentiva queda manifiesta en estrategias, como iniciar nuevos procedimientos, en mostrar resiliencia a través de una CA instrumental «apática» — los solicitantes no son seres indiferentes, pero es algo que hacen en forma consciente para lograr ciertos fines- ya que, en el fondo, la esperanza se proyecta por encima de la incertidumbre. 


\section{Referencias bibliográficas}

1 Amenusca, Cristina. (2011). Percepciones sobre los migrantes mexicanos en el condado de Gwinnett, Georgia: fricciones y encuentros en el sur estadunidense. Norteamerica. 6, pp. 35-70.

2. Arriola, Luis A. (2018). Aportes para evaluar el desempeño inicial del Programa Frontera Sur. En: Castellanos López, Nayar (coord.). Procesos migratorios en la Centroamérica del siglo Xxı (pp. 23-46). México, D. F.: Universidad Nacional Autónoma de México.

3. Avendaño, Cecilia; Krause, Marianney Winkler, María. (1993). Representaciones sociales y teorías subjetivas: relevancia teórica y aplicaciones empíricas. Psyche, 2 (1), pp. 107-114.

4. Basok, Tanya \& Rojas, Martha. (2018). Precarious Legality: Regularizing Central American migrants in Mexico. Ethnic and Racial Studies, 41 (7), pp. 1274-1293. DOI: 10.1080/01419870.2017.1291983

5. Booth, John A.; Wade, Christine \& Walker, Thomas. (2014). Understanding Central America: Global Forces, Rebellion and Change. New York: Routledge.

6. Braithwaite, Alex; Chu, Tiffany S.; Curtis, Justin \& Ghosn, Faten. (2019). Violence and Perception of Risk Associated with Hosting Refugees. Public Choice, 178, pp. 473-492. DOI: 10.1007/s11127-018-0599-0

7. Brown, Kate. (2011). "Vulnerability»: Handle with Care. Ethics and Social

[204] Welfare, 5 (3), pp. 313-321. DOI: 10.1080/17496535.2011.597165

8. Buzan, Barry; Wæver, Ole \& de Wilde, Jaap. (1998). Security: A New Framework for Analysis. Boulder: Lynne Rienner.

9. Clark-Kazak, Christina. (2009). Representing Refugees in the Life Cycle: A Social Age Analysis of United Nations High Commissioner for Refugees Annual Reports and Appeals 1999-2008. Journal of Refugee Studies, 22 (3), pp. 302-322. DOI: 10.1093/ jrs/fep012

10. Comisión Mexicana de Ayuda a Refugiados (Comar). (2019, enero 14). Boletín estadístico de solicitantes de refugio en México. Comar 2017. Gobierno de México. https://www.gob.mx/comar/articulos/boletin-estadistico-de-solicitantes-de-refugio-enmexico-182244?idiom $=$ es

11. Coraza, Enrique. (2018). Pensando el espacio transfronterizo MéxicoGuatemala y sus movilidades humanas. En: Arriola, Luis y Coraza, Enrique (eds.). Ráfagas y vientos de un sur global. Movilidades recientes en estados fronterizos del sur-sureste de México (pp. 25-51). San Cristóbal de Las Casas \& New York: Ecosur \& Peter Lang.

12. Crawley, Heaven \& Hagen-Zanker, Jessica. (2019). Deciding Where to Go: Policies, People and Perceptions Shaping Destination Preferences. International Migration, 57 (1), pp. 20-35. DOI: 10.1111/imig.12537 
13. Cruz, Tania. (2011). Racismo cultural y representaciones de inmigrantes centroamericanas en Chiapas. Migraciones Internacionales, 6 (2), pp. 133-157.

14. Delgado, David. (2008). Percepciones de la inmigración e integración en Costa Rica. Papeles de Población, 14 (57), pp. 56-91.

15. Fajardo, Rocío y Soriano, Rosa. (2016). La construcción mediática de la migración en el Mediterráneo: ¿no-ciudadanía en la prensa española? Revista Internacional de Estudios Migratorios, 6 (1), pp. 141-169. DOI: 10.25115/riem. v6i1.419

16. Festinger, Leon; Schachter, Stanley \& Back, Kurt. (1950). Social Pressures in Informal Groups: A Study of a Housing Community. New York: Harper. DOI: 10.2307/3707362

17. Fozdar, Farida \& Torezania, Silvia. (2008). Discrimination and Well-Being: Perceptions of Refugees in Western Australia. International Migration Review, 42 (1), pp. 30-63. DOI: 10.1111/j.1747-7379.2007.00113.x

18. Franzoi, Stephen. (2007). Psicología Social. México, D. F.: McGraw-Hill.

19. Galindo, Sandra E. (2019). Las palabras importan: representación de los inmigrantes mexicanos en periódicos de México y Estados Unidos. Migraciones Internacionales, 10 (36). DOI: 10.33679/rmi.v1i1.2024

20. Galton, Francis. (1879). Psychometric experiments. Brain, 2, pp. 149-162. DOI: 10.1093/brain/2.2.149

21. Gill, Nick; Caletrío, Javier \& Mason, Victoria. (2011). Introduction: Mobilities and Forced Migration. Mobilities, (6) 3, pp. 301-316. DOI: 10.1080/17450101.2011.590032

22. Green, Linda. (2011). The Nobodies: Liberalism, Violence and Migration. Medical Anthropology, 30 (4), pp. 366-385. DOI: 10.1080/01459740.2011.576726

23. Gross, Richard. (2007). Psicología. La ciencia de la mente y la conducta. México, D. F.: El Manual Moderno.

24. Hercowitz-Amir, Adi; Raijman, Rebeca \& Davidov, Eldad. (2017). Host or Hostile? Attitudes towards Asylum Seekers in Israel and in Denmark. International Journal of Comparative Sociology. 58 (5), pp. 416-439. DOI: 10.1177/0020715217722039

25. Hernández, Roberto; Fernández, Carlos y Baptista, Pilar. (2014). Metodología de la Investigación. México, D. F.: Mc Graw-Hill.

26. Hiskey, Jonathan T.; Cordova, Abby; Malone, Mary F. \& Orcés, Diana M. (2018). Leaving the Devil You Know: Crime Victimization, US Deterrence Policy, and the Emigration Decision in Central America. Latin American Research Review. 53 (3), pp. 429-447. DOI: 10.25222/larr.147

27. Human Rights Watch. (2016, marzo 31). Puertas Cerradas. El fracaso de México en la protección de niños y niñas migrantes de América Central. Recuperado de https:/www.hrw.org/es/report/2016/03/31/puertas-cerradas/el-fracaso-de-mexicoen-la-proteccion-de-ninos-refugiados-y 
28. Kimble, Charles; Hirt, Edward; Díaz-Loving, Rolando; Hosch, Harmon; Lucker, G. William y Zárate, Michael. (2002). Psicología social de las Américas. México, D. F.: Pearson Educación de México.

29. Lusk, Mark; Terrazas, Sam; Caro, Janette; Chaparro, Perla \& Puga, Delia. (2019). Resilience, Faith, and Social Supports among Migrants and Refugees from Central America and Mexico. Journal of Spirituality in Mental Health. DOI: 10.1080/19349637.2019.1620668

30. Mainwaring, Cetta. (2016). Migrant Agency: Negotiating Borders and Migration Controls. Migration Studies, 4 (3), pp. 289-308. Doi:10.1093/migration/ mnw013

31. Malkki, Lisa. (1995). Refugees and Exile: From "Refugee Studies» to the National Order of Things. Annual Review of Anthropology, 24, pp. 495-523. DOI: 10.1146/annurev.an.24.100195.002431

32. Martínez L., Soledad. (2006). Representaciones sociales, inmigración y mujeres: Hegemonía y polisemia. Theoria. 15 (2), pp. 61-67.

33. Masanet, Erika. (2006). El proceso migratorio brasileño hacia España desde la mirada de la sociedad de origen: las percepciones sociales en torno al contexto de partida y de llegada. Revista Alternativas. Cuadernos de Trabajo Social, 14, pp. 71-93. DOI: 10.14198/ALTERN2006.14.6

34. McAuliffe, Marie \& Jayasuriya, Dinuk. (2016). Do Asylum Seekers and Refugees Choose Destination Countries? Evidence from Large-Scale Sin Australia, [206] Afghanistan, Bangladesh, Pakistan and Sri Lanka. International Migration, 54 (4), pp. 44-59. DOI: 10.1111/imig.12240

35. Montero, Gabriela. (2006). Las representaciones sociales de los emigrantes ecuatorianos en España sobre el proceso migratorio. Revista Alternativas, 14, pp. 3548. DOI: 10.14198/ALTERN2006.14.3

36. Morales, Orlando G. (2015). Si hay negros, que no se diga, si hay racismo, que se disimule. Migrantes afrodescendientes en la prensa argentina. InterSciencePlace, 10 (4), pp. 81-206. DOI: 10.6020/1679-9844/v10n4a5

37. Moscovici, Serge \& Marková, Ivana. (1998). Presenting Social Representations: A Conversation. Culture and Psychology, 4 (3), pp. 371-410. DOI: 10.1177/1354067X9800400305

38. Moscovici, Serge. (1961). La psychanalyse, son image, son public. Paris: Presses Universitaires de France.

39. Moscovici, Serge. (1988). Notes towards a Description of Social Representations. European Journal of Social Psychology, 18, pp. 211-250.

40. Murray, Kate \& Marx, David. (2013). Attitudes toward Unauthorized Immigrants, Authorized Immigrants, and Refugees. Cultural Diversity \& Ethnic Minority Psychology, 19 (3), pp. 332-341. DOI: 10.1037/a0030812 
41. Nef, Jorge. (1999). Human Security and Mutual Vulnerability: The Global Political Economy of Development and Underdevelopment. Ottawa: International Development Research Centre.

42. O'Higgins, Aoife. (2012). Vulnerability and Agency: Beyond an Irreconcilable Dichotomy for Social Service Providers Working with Young Refugees in the UK. New Directions for Child and Adolescent Development, 136, pp. 79-91. DOI: 10.1002/ cad.20012

43. Orgocka, Aida. (2012). Vulnerable Yet Agentic: Independent Child Migrants and Opportunity Structures. New Directions for Child and Adolescent Development, 136, pp. 1-111. DOI: 10.1002/cad.20007

44. Osgood, Charles E.; Suci, George J. \& Tannenbaum, Percy. H. (1957). The Measurement of Meaning. Illinois: University of Illinois.

45. Oxford, Connie G. (2005). Protectors and Victims in the Gender Regime of Asylum. NWSA Journal, 17 (3), pp. 18-38. DOI: 10.2979/NWS.2005.17.3.18

46. Patiño, Marysol. (2005). Representaciones sociales, percepciones e imaginarios de jóvenes ecuatorianos artesanos/indígenas y artistas/estudiantes, inmigrantes en Francia. Revista Alternativas, 13, pp. 165-195. DOI: 10.14198/ALTERN2005.13.11

47. Pedone, Claudia. (2002). Las representaciones sociales en torno a la inmigración ecuatoriana a España. Íconos, 14, pp. 56-66. DOI: 10.17141/iconos.14.2002.584

48. Quezada, Margarita de J. (2007). Migración, arraigo y apropiación del espacio en la recomposición de identidades socioterritoriales. Cultura y Representaciones Sociales, 2 (3), pp. 35-67.

49. Ramos, Diego N.; Coraza, Enrique y Martínez, Santiago. (2018). Miradas desde el sur de México sobre seguridad y frontera. URVIO, 23, pp. 57-32. DOI: 10.17141/urvio.23.2018.3551

50. Stewart, Emma. (2005). Exploring the Vulnerability of Asylum Seekers in the UK. Population, Space and Place, 11, pp. 499-512. DOI: 10.1002/psp.394

51. Torres, Osvaldo y Garcés, Alejandro. (2013). Representaciones sociales de migrantes peruanos sobre su proceso de integración en la ciudad de Santiago de Chile. Polis, 12 (35). DOI: 10.4067/S0718-65682013000200014

52. Townsend, Jacob \& Christel Oomen. (2015). Before the Boat: Understanding the Migrant Journey. Bruselas: Migration Policy Institute Europe.

53. Treviño-Rangel, Javier. (2016). What Do We Mean When We Talk about the Securitization of International Migration in Mexico: A Critique. Global Governance, 22 (2), pp. 289-304. DOI: 10.1163/19426720-02202007

54. Utas, Mats. (2005). Victimcy, Girlfriending, Soldiering: Tactic Agency in a Young Woman's Social Navigation of the Liberian War Zone. Anthropological Quarterly, 78 (2), pp. 403-430. DOI: 10.1353/anq.2005.0032

55. Wæver, Ole. (1995). Securitization and Desecuritization. En: Lipschutz, Ronnie D. (ed.). On Security (pp. 46-86). New York: Columbia University. 
56. Washington Office on Latin America (WOLA). (2017, noviembre). Justicia olvidada. La impunidad de las violaciones a derechos humanos cometidas por soldados en México. Recuperado de https://www.wola.org/es/analisis/informe-de-wolajusticia-olvidada-la-impunidad-de-las-violaciones-derechos-humanos-cometidas-porsoldados-en-mexico/

57. Watson, Scott D. (2009). The Securitizaton of Humanitarian Migration. Digging Moats and Sinking Boats. London \& New York: Routledge. DOI: 10.4324/9780203876794

58. Worchel, Stephen; Cooper, Joel; Goethals, George R. y Olson, James. (2002). Psicología social. México, D. F.: Thomson.

59. World Values Survey (WVS). (s. f). Online Data Analysis. World Values Survey Wave 6: 2010-2014. Mexico. V39. Neighbours: Immigrant/foreign workers. Retrieved from http://www.worldvaluessurvey.org/WVSOnline.jsp 